Report No. BMI-1198

UC-81 Reactors - Power (TID-4500, 13th Ed.)

Contract No. W-7405-eng-92

MODEL STUDIES OF FLOW IN THE THERMALSHIELD PASSAGES OF THE PWR REACTOR

by

Lawrence J. Flanigan

Herbert R. Hazard

June 26, 1957

BATTELLE MEMORIAL INSTITUTE

505 King Avenue

Columbus 1, Ohio 


\section{DISCLAIMER}

This report was prepared as an account of work sponsored by an agency of the United States Government. Neither the United States Government nor any agency Thereof, nor any of their employees, makes any warranty, express or implied, or assumes any legal liability or responsibility for the accuracy, completeness, or usefulness of any information, apparatus, product, or process disclosed, or represents that its use would not infringe privately owned rights. Reference herein to any specific commercial product, process, or service by trade name, trademark, manufacturer, or otherwise does not necessarily constitute or imply its endorsement, recommendation, or favoring by the United States Government or any agency thereof. The views and opinions of authors expressed herein do not necessarily state or reflect those of the United States Government or any agency thereof. 


\section{DISCLAIMER}

Portions of this document may be illegible in electronic image products. Images are produced from the best available original document. 
ABSTRACT • . . . . . . . . . . . . . . . . . . . 1

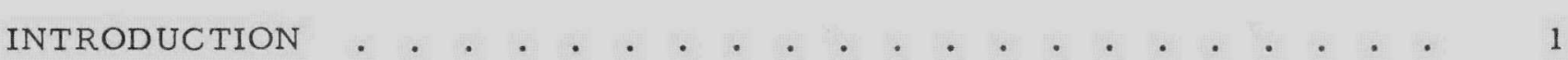

STUDIES IN QUARTER-SCALE MODEL . . . . . . . . . . . . . . 3

Description of Model . . . . . . . . . . . . . . . 3

QUARTER-SCALE MODEL THERMAL-SHIELD INSTRUMENTATION . . . . 8

Quarter-Scale Model Setup and Operation . . . . . . . . . 9

SUMMARY OF DATA FROM QUARTER-SCALE FLOW MODEL . . . . . . 9

Flow Direction in Thermal-Shield Coolant Passages of the

Quarter-Scale Model . . . . . . . . . . . . . 10

Orifice Coefficients for the Flow Baffle of the Quarter-Scale Model . . 10

Tests in Quarter-Scale Model With Blank Flow Baffle . . . . . . . 17

STUDIES IN 1.5-SCALE MODEL . . . . . . . . . . . . . . . . 17

DESCRIPTION OF 1.5-SCALE FLOW MODEL OF THERMAL-SHIELD

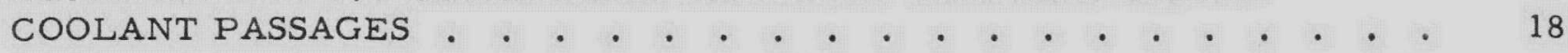

Instrumentation of 1.5-Scale Model . . . . . . . . . . . . 21

Operation of the 1.5-Scale Model . . . . . . . . . . . 21

SUMMARY OF DATA FROM 1.5-SCALE MODEL OF PWR THERMALSHIELD COOLANT PASSAGES . . . . . . . . . . . . . . . 22

Typical Static-Pressure Data for the 1.5-Scale Model . . . . . . . 22 Momentum Losses in the 1.5-Scale Model . . . . . . . . . . . 22 Turning Loss, Channel 1 to Channel 3 for 1.5-Scale Model . . . 26 Turning Loss, Channel 1 to Channel 2 for 1.5-Scale Model . . . 28 Analysis of Turning Losses as Orifice Coefficients . . . . . . 28 Obstruction Loss in Channel 2 for 1.5-Scale Model . . . . . . 31 Relation of Momentum Losses to Reynolds Number for

APPLICATION OF MODEL DATA TO DESIGN OF PROTOTYPE SHIELD

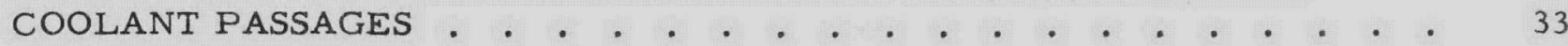

Flow Distribution and Pressure Loss in Shield Passages . . . . . . 33 Effects of Leakage Through Seal at Top of Channel 3 on Shield Flow . . 37 


\title{
MODEL STUDIES OF FLOW IN THE THERMAL- SHIELD PASSAGES OF THE PWR REACTOR
}

\author{
Lawrence J. Flanigan and Herbert R. Hazard
}

\begin{abstract}
Flow studies were made to obtain data for design of flow restrictions in thermalshield coolant passages and for design of the flow baffle for the PWR reactor. The studies were made using air, in both a quarter-scale model of the reactor and in a 1.5-scale model of a section of the flow passages. Data obtained from the two models were then used as a basis for selecting sizes of restricting orifices and short tubes for the prototype, and for design of the flow baffle to provide the correct flow through the shield passages.
\end{abstract}

In the model studies, the flow through the thermal-shield passages did not prove proportional to total reactor flow. Instead, the percentage of flow through the shield passages diminished as the number of operating loops was increased because of an increase in the flow coefficient of the perforated flow baffle. Detailed studies of flow in shield passages showed that there may be considerable variation in both velocity and direction of flow in Channel 1, the outer channel, resulting from asymmetrical flow conditions in the lower plenum. However, mass transfer exists throughout the cooling annuli under all operating conditions; therefore, no stagnant regions are present, and adequate cooling will be provided.

\section{INTRODUCTION}

In the PWR design, the thermal shields surrounding the core are arranged, as shown in Figure 1, so that they create annuli through which flow can be directed to provide adequate cooling of the pressure vessel and the thermal shields. Channel 1 , the outer annulus, is the passage between the pressure vessel and the outer shield. The middle annulus, Channel 2 , is the annulus between the outer and inner thermal shields. The inner thermal shield and the core cage form Channel 3, the inner annulus. Potential which is provided by a pressure differential across the flow baffle attached to the outer thermal shield forces fluid to flow up through Channel 1, the outer annulus, where it is distributed to Channels 2 and 3 and returned to the low-pressure side of the flow baffle. Flow from Channel 1 is directed into Channel 2 through orifices located at the top of the outer shield. Short tubes, located below the orifices in the outer shield, pass flow from Channel 1 directly into Channel 3. The downward flows from Channels 2 and 3 combine at the low-pressure side of the baffle and join the main body of flow entering the core. To insure adequate cooling of the pressure vessel and thermal shields, it is essential that sufficient flow pass through the annuli.

The purpose of this study* was to determine the sizes of the flow passages involved, so that adequate cooling of the thermal shields would be achieved, and to study flow patterns in the various annuli, to be sure that uncooled areas did not exist.

\footnotetext{
- This is the third of several reports describing PWR flow studies conducted at Battelle for the Bettis Laboratory of the Atomic Energy Commission operated by the Westinghouse Electric Corporation. Reports issued previously were BMI-1141, "Studies of Flow Distribution in the Core of a Quarter-Scale Flow Model of the PWR Reactor", and BMI-1172, "Studies of Mixing in the Lower Plenum of a Quarter-Scale Flow Model of the PWR Reactor".
} 

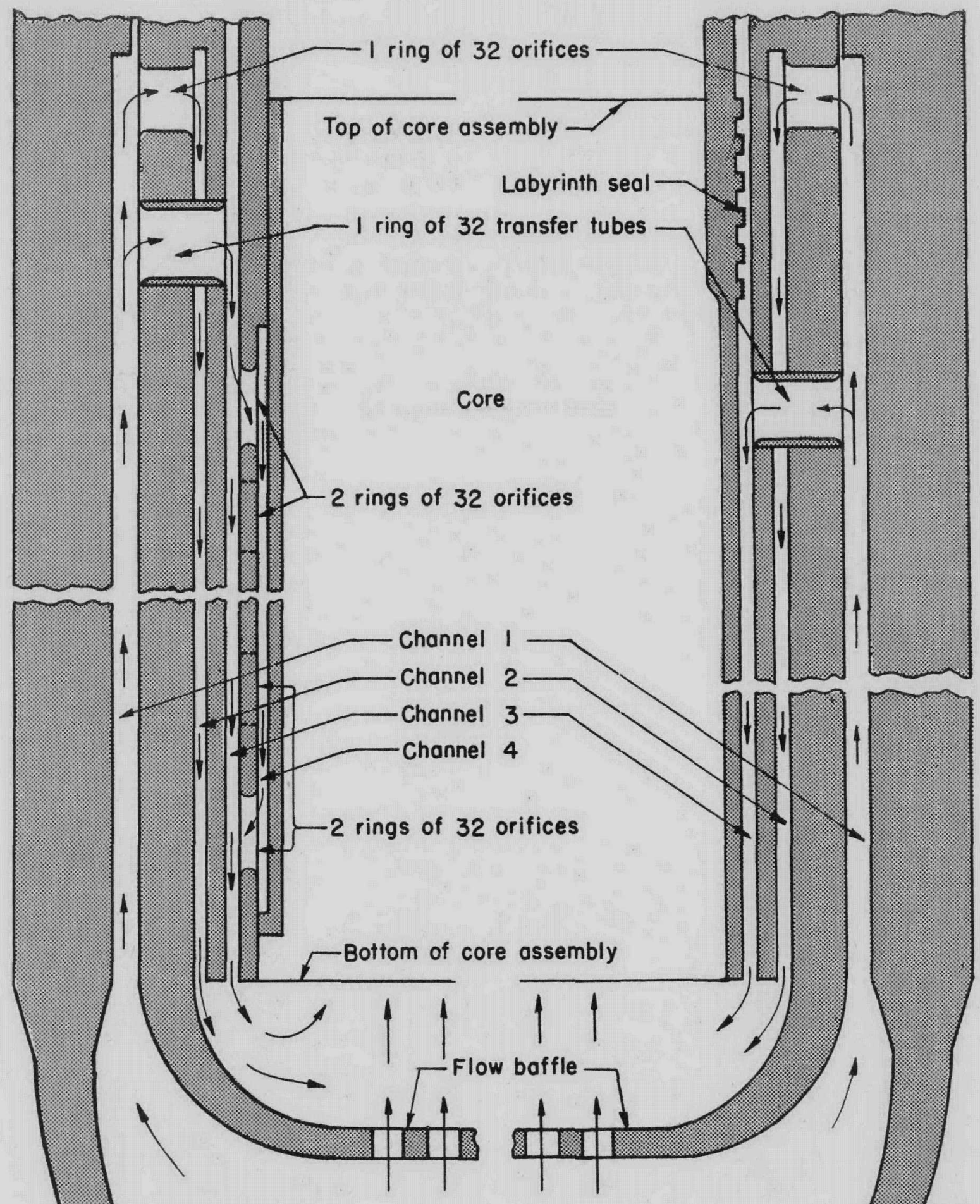

Lower plenum 
The studies were made using air in models designed to simulate flow conditions in the PWR. Part of the studies were made in a quarter-scale model of the components contained in the pressure vessel.

At the time of fabrication of the quarter-scale model, the reference design of the thermal shield contained four cooling annuli as shown in Figure 1. As previously mentioned, the design of the prototype was changed later to one using three cooling annuli.

Therefore, in order to provide information for the design of the flow passages, it was necessary to construct another model, the 1.5-scale model, containing the three flow channels of the modified prototype design. This model was a narrow section of the flow passages rather than a complete annulus as in the other model. While it was not possible to study flow patterns in the annuli of this model, it was more satisfactory for determining the size of flow passages because the Reynolds number was closer to that of the prototype.

Thus, two models were used in this study, the quarter-scale model being used primarily for flow-distribution studies, the 1.5-scale model primarily for obtaining information on the sizes required for flow passages. Studies in the quarter-scale model will be described first.

\section{STUDIES IN QUARTER-SCALE MODEL}

Description of Model

The quarter-scale flow model was designed to simulate flow conditions throughout the PWR reactor with the exception of those within the fuel assemblies; these were simulated with orificed tubes having proper flow resistances. The model was constructed of aluminum and stainless steel throughout, except for the upper and lower domes, which were constructed of glass-fiber reinforced plastic. The model was designed at the Bettis Laboratory and constructed by the Aircraft Gas Turbine Division of Westinghouse Electric Corporation, and was supplied with internal instrumentation. External instruments were added at Battelle.

Figure 2 is a photograph of the quarter-scale flow model set up for tests. Four blowers at the left supplied air for tests and the large manometer board at the right was used to record pressures throughout the model. The highest air flow used in the quarter-scale model was $5.5 \mathrm{lb}$ air per sec at 5.2 psi.

Figure 3 is a vertical section of the quarter-scale flow model showing the general arrangement of the pressure shell, the inlets and outlets, the thermal shields, the flow baffle, the core, the control-rod guides, the hold-down barrel, and the internal instrumentation.

Figure 4 is a horizontal section of the model showing the arrangement of the thermal shields, the shield-passage instrumentation, and the core.

Figure 5 is a photograph of the flow baffle which is located under the core. 


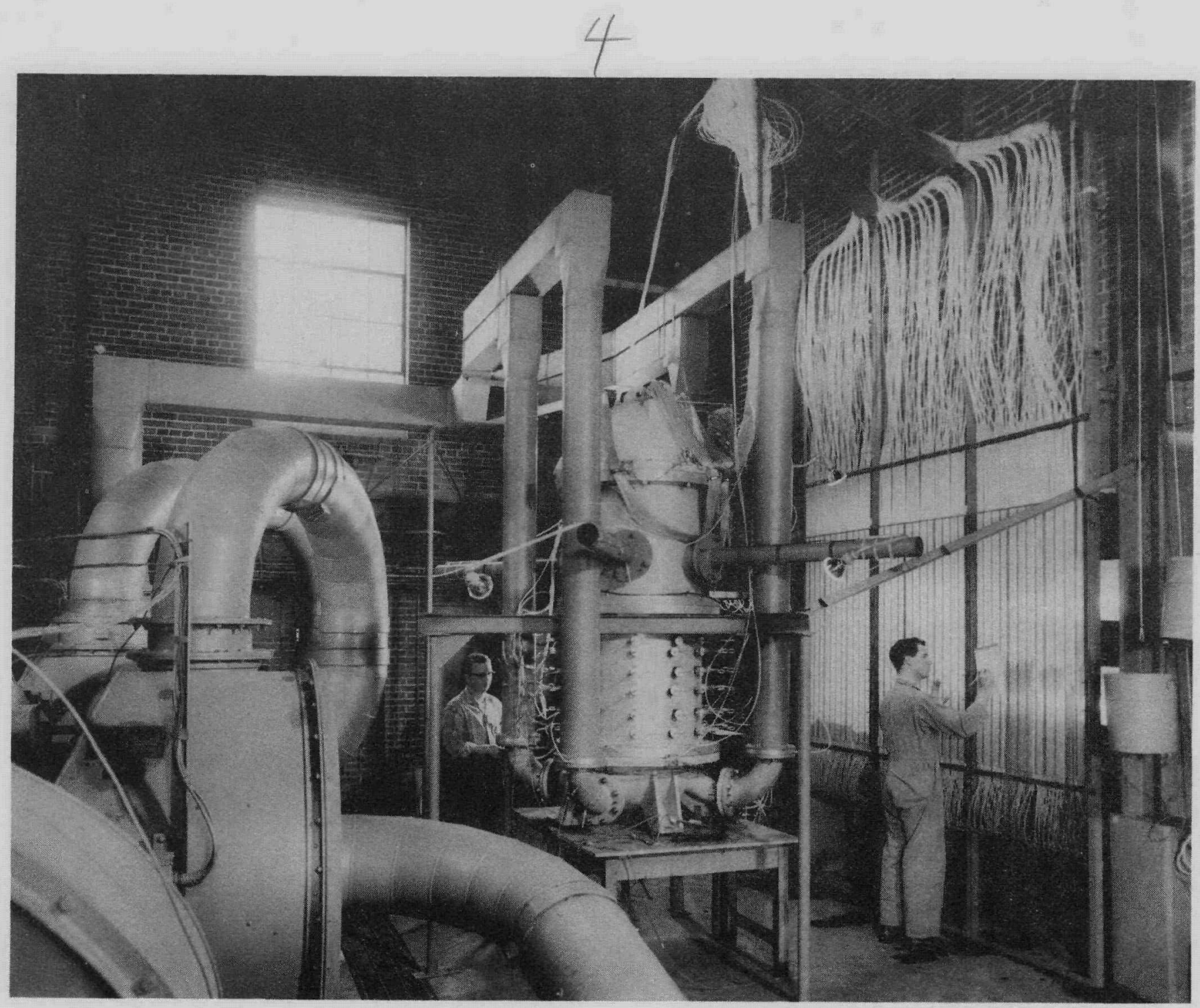

FIGURE 2. PHOTOGRAPH OF QUARTER-SCALE FLOW MODEL OF PWR REACTOR INSTALLED FOR AIR-FLOW STUDIES 


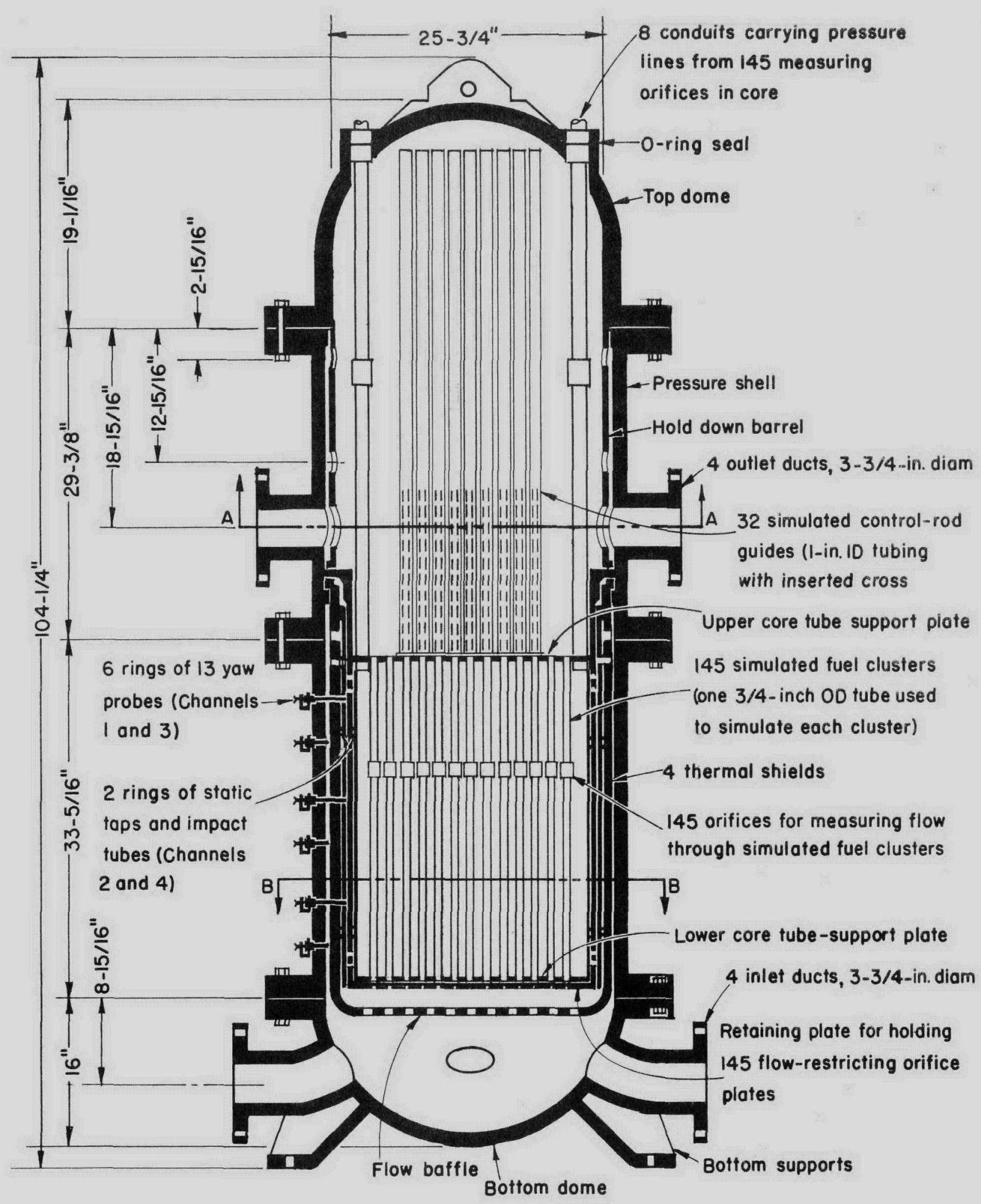

FIGURE 3. QUARTER-SCALE FLOW MODEL OF PWR REACTOR VERTICAL SECTION 


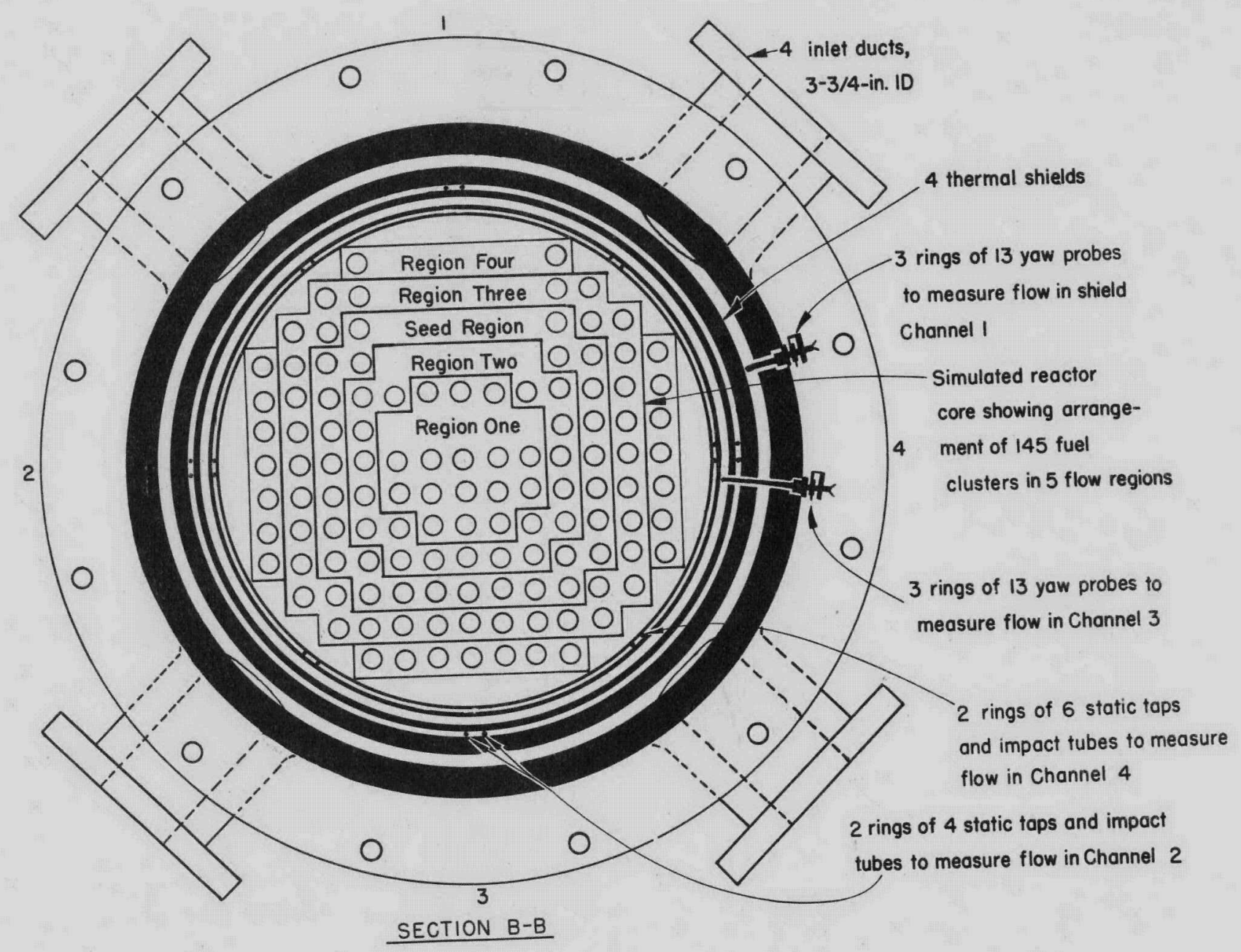

FIGURE 4. QUARTER-SCALE FLOW MODEL OF PWR REACTOR - HORIZONTAL SECTION THROUGH CORE 


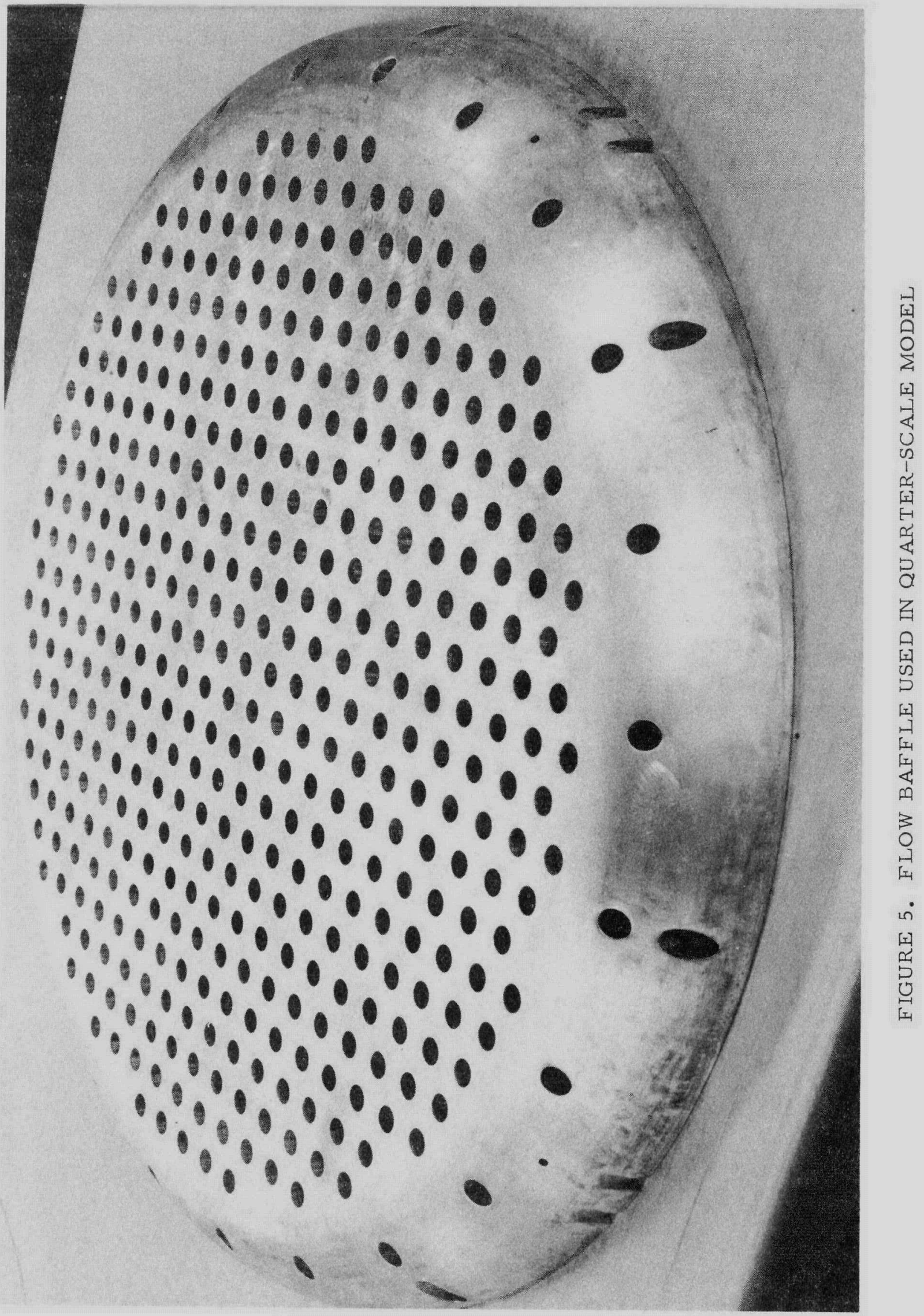


The flow path through the thermal-shield region is different in this model than in the prototype, for which the flow path was described previously. The flow path in the model is best seen in Figure 1. Air enters the pressure vessel through two or more of the inlets at the bottom. The flow baffle introduces a flow resistance, so that about 85 per cent of the flow passes through it, while the other 15 per cent is forced to flow around the baffle, through the thermal-shield region.

The flow in the thermal-shield annuli is upward to the top of Channel 1, where part of the flow passes through holes to Channel 2, and the other part passes through tubes between Channel 1 and Channel 3. This portion of the flow is then divided between Channels 3 and 4 by holes in the thermal shield between these channels. The flow in Channels 2, 3, and 4 is then downward. Near the bottom of the thermal shields, the flow in Channel 4 is transferred to Channel 3 , and then all the coolant mixes with the main portion of the flow which passed through the holes in the flow baffle. Thus, the pressure drop across the flow baffle provides the driving force for flow through the thermal-shield passages.

\section{QUARTER-SCALE MODEL THERMAL-SHIELD INSTRUMENTATION}

Instrumentation in the thermal-shield passages of the quarter-scale model was designed to permit determination of over-all pressure drop, quantities of flow in each passage, and directions of flow in Channel 1 and Channel 3. The location of the instrumentation is shown in Figures 3 and 4.

The static pressure in the lower plenum was measured by a ring of pressure taps just below the inlet to Channel 1. The static pressure at the outlets of the shield passages was measured by a ring of pressure taps installed in the flow baffle just below the outlets of the channels. The difference between these two pressures was the pressure loss across the shield passages.

Flow in Channel 2 and Channel 4 was measured with fixed total-pressure probes and static-pressure taps. In Channel 2, four measuring stations were spaced around the channel at each of two locations, one near the top and one near the bottom. In Channel 4 , six stations were provided at each of two elevations.

In Channel 1 and Channel 3, flow velocities and directions were measured using two-hole cylindrical yaw probes. These probes were 1/4 in. in diameter and were fitted with O-rings where they passed through shields and through the outer shell, to prevent leakage. Each probe had two pressure taps spaced $78.5 \mathrm{deg}$ apart, and at a distance from the end of the probe locating them at the center of the channel. A protractor scale and pointer provided a means of reading the flow direction. Three rings of yaw probes, at three elevations, were installed in Channel 1 and Channel 3. In each ring there were 13 yaw probes; these were not equally spaced. In addition to the original 78 yaw probes supplied, 23 additional probes were installed near the bottom of Channel 1 to extend the studies of downward flow found with the three-loop operating configuration.

In use, each yaw probe was attached to an inclined manometer and rotated until

the manometer was balanced, indicating that the probe was pointed upstream. The flow direction was then read from the probe protractor and the static pressure was read by 
balancing the pressure from either side of the probe against a reference pressure close to static pressure. The probe was then rotated 39-1/4 deg to place a pressure tap directly upstream, and total pressure was read against the same reference pressure. Velocity pressures generally ranged from $0.01 \mathrm{in}$. of water to $0.30 \mathrm{in}$. of water, so that a precision inclined manometer and extreme care were required to obtain data of satisfactory accuracy. The sensitivity of the manometers used was $0.001 \mathrm{in}$. of water. Absolute pressures, of the order of 20 psia, were measured by attaching representative shield-passage static taps to the large water-manometer panel.

\section{Quarter-Scale Model Setup and Operation}

The model was set up so that flow to each inlet and outlet could be closely controlled. Details of piping and external instrumentation may be seen in Figure 2.

The model was installed with 90 -deg elbows on each inlet to simulate prototype installation. A flow-measuring nozzle was installed at each inlet to measure flow and to determine when flow through inlets was equalized. Flow to individual inlets was adjusted by varying the insertion of $3 / 8-\mathrm{in}$. rods into the air stream in the elbow. The approach piping, carrying air at pressures to 6 psi and temperatures to $190 \mathrm{~F}$, was constructed with turning vanes in the elbows to minimize flow disturbances approaching the inlet nozzles.

For core and shield studies, the outlets were discharged to the room through tubes 10 diameters long. Flow through the outlets was equalized by varying the insertion of 3/8-in. rods until impact pressures at the outlet ends of the outlet pipes were equal.

In tests with simulated operation of less than four loops, plates were installed between flanges at inactive inlets and outlets.

Pressure taps from the 145 measuring orifices in the core, and static-pressure taps in the lower plenum, upper plenum, and shield regions, were connected to a specially constructed manometer board having 360 tubes, each suitable for measurement of pressures up to $170 \mathrm{in.}$ of water.

\section{SUMMARY OF DATA FROM QUARTER-SCALE FLOW MODEL}

The quarter-scale flow model was used to study the effects of various operating conditions on quantities of flow through the thermal-shield coolant passages, on distribution of flow around the passages, and on flow directions and velocities throughout the passages. As secondary considerations, the distribution of flow among passages was determined. These data were not directly applicable to the prototype because of changes in design of the prototype after model construction; the model had four thermal shields, compared with only three in the final prototype design.

In addition to shield-passage flow data, the flow characteristics of the flow baffle under the core were detemined. The resistance of this baffle dictates the quantity of flow passing through the shield passages. 
Flow Direction in Thermal-Shield Coolant Passages

of the Quarter-Scale Model

Flow directions and velocities in the thermal-shield passages of the quarter-scale model were measured by means of two-hole cylindrical yaw probes in Channel 1 and Channel 3, and velocities were measured by impact probes and static taps in Channels 2 and 4 . When operating with two loops and with four loops, flow was generally upward in Channel 1 and downward in Channels 2, 3, and 4, with good velocity distribution. When operating with three loops, however, the flow in Channel 1 was unbalanced. Most of the flow was upward through the half of the shield passage above the closed loop, and downward flow was observed over a substantial area above the center operating loop. Twenty-three additional yaw probes were installed above the center operating loop to fully explore velocity patterns in this area.

Figure 6 is a data plot showing the directions and velocities of air flow in Channel 1 with four loops operating. Arrows are located at yaw-probe locations and indicate flow direction; numbers indicate flow velocities. Velocities of water flow in the prototype are smaller than the air-flow velocities shown by a factor of 6.2. The data plot is scaled to model proportions.

Figure 7 shows the flow pattern in Channel 1 with two opposed loops in operation. Although directions of flow depart considerably from the vertical, mass transfer exists throughout the cooling annuli.

Figure 8 shows flow directions and velocities in Channel 1 with three loops operating. In this figure, a region of disturbed flow is shown above Inlet 1-2, the center of the three operating inlets. The close spacing of yaw probes shown in this figure is the result of adding 23 probes to more fully explore conditions in this area.

Figure 9 is an enlarged detail of flow directions and velocities in the area above Inlet 1-2 for three-loop operation. An attempt has been made to indicate flow lines, in order to better judge the extent of any regions of inadequate cooling. Although considerable downward flow was found above Inlet 1-2, the lowest air velocity measured was $12 \mathrm{fps}$. This is equivalent to a water velocity of $2 \mathrm{fps}$ in the prototype.

Yaw-probe measurements in Channel 3 showed that the variations in flow direction from the vertical did not exceed $10 \mathrm{deg}$ under any operating condition. Although directions of flow in Channels 2 and 4 could not be measured with the installed fixed probes, flow velocities were very uniform throughout each channel, and it is assumed that flow directions were similar to those in Channel 3.

Orifice Coefficients for the Flow Baffle

of the Quarter-Scale Model

It has been pointed out that the flow through the thermal-shield passages has as its driving force the pressure drop across the perforated flow baffle, under the core. In order to design the prototype to obtain the proper shield-passage flow, it was, therefore, necessary to know flow-baffle orifice coefficients. These were determined in the quarter-scale model with simulated two-loop, three-loop, and four-loop operating conditions, using several values of air flow for each condition. For each determination, 


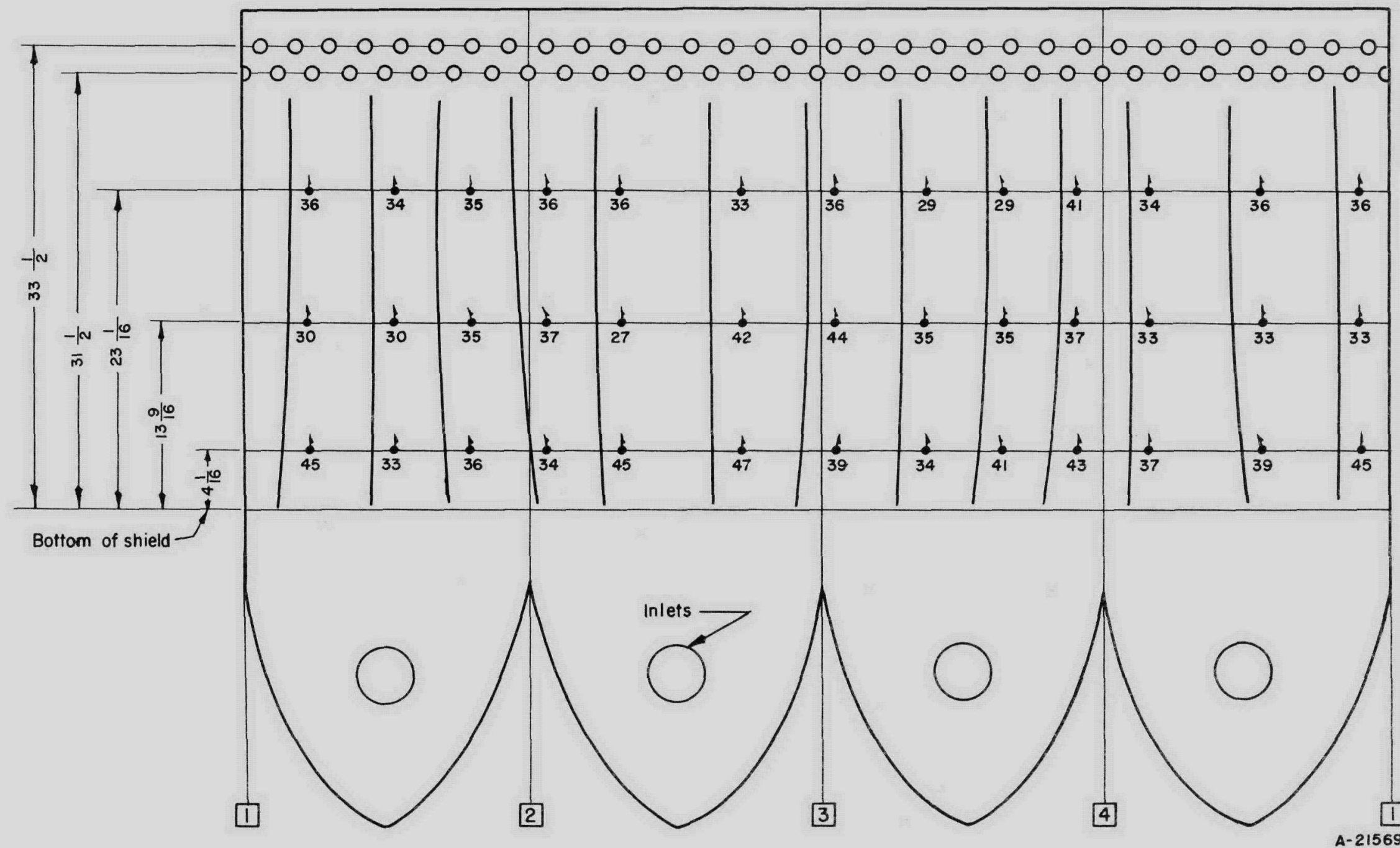

FIGURE 6. FLOW PATTERN IN CHANNEL I WITH FOUR-LOOP OPERATION Arrows indicate direction and numbers indicate air velocity in fps. 


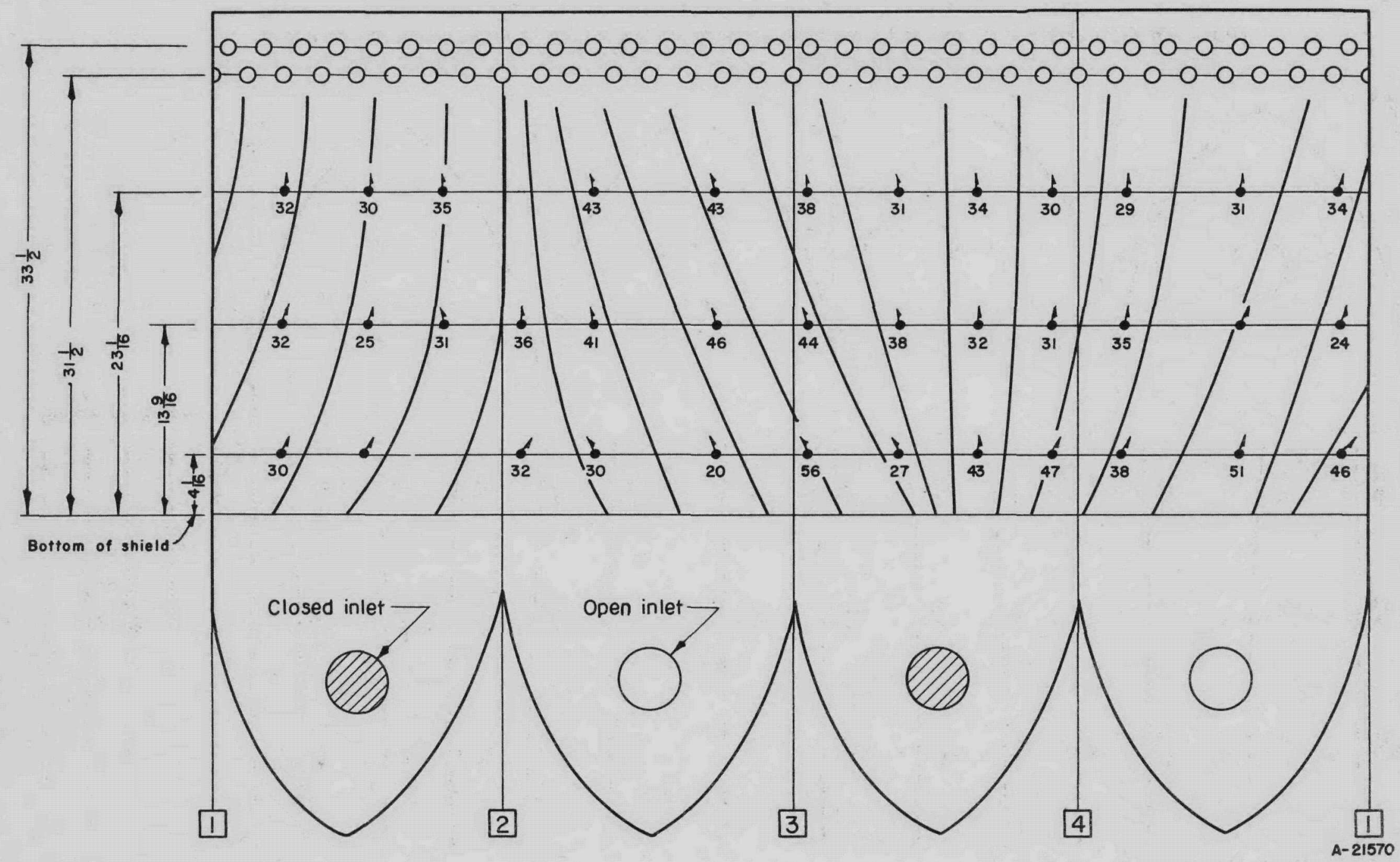

FIGURE 7. FLOW PATTERN IN CHANNEL 1 WITH TWO OPPOSED LOOPS OPERATING Arrows indicate direction and numbers indicate air velocity in fps. 


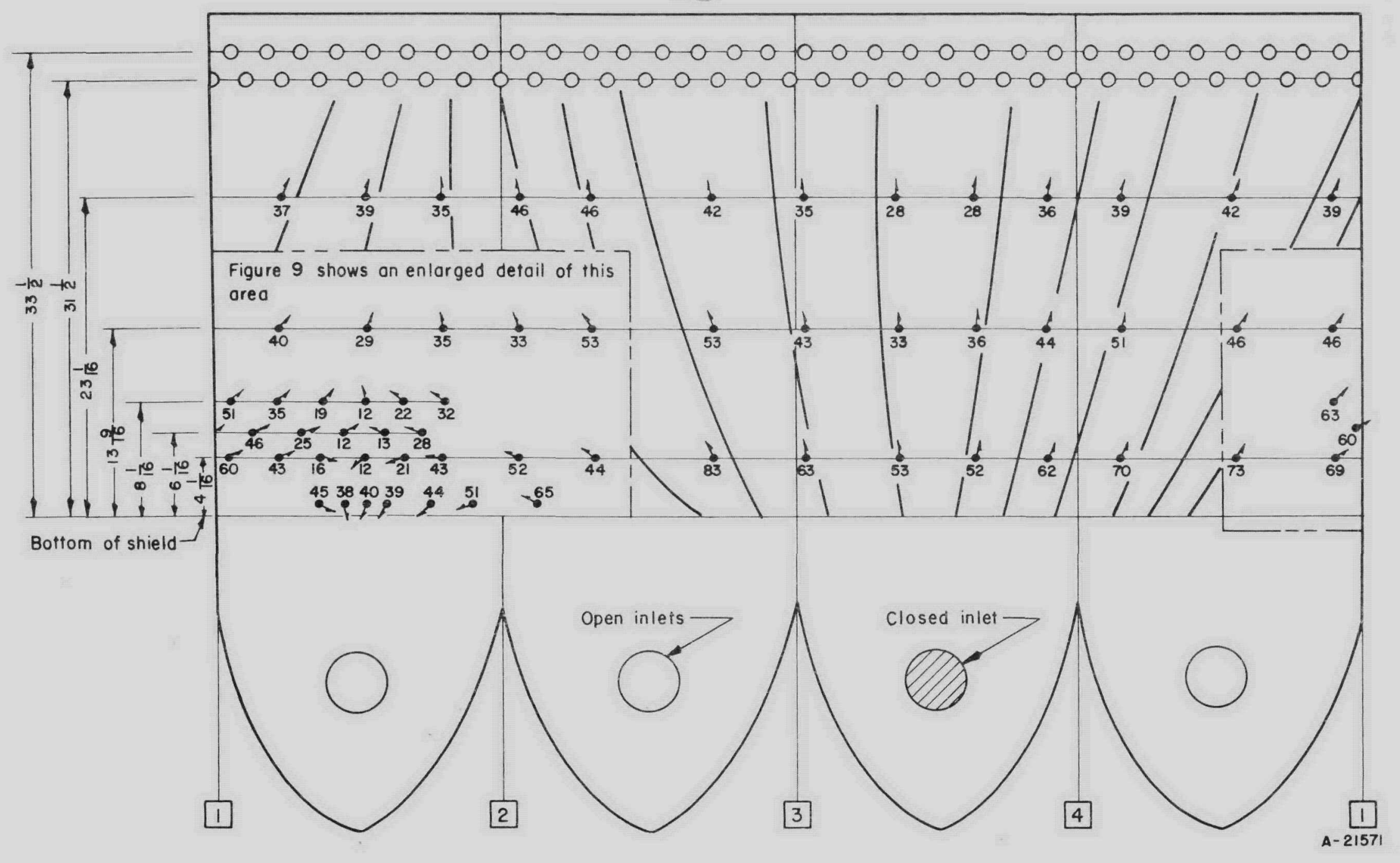

FIGURE 8. FLOW PATTERN IN CHANNEL 1 WITH THREE-LOOP OPERATION Arrows indicate direction and numbers indicate air velocity in fps. 


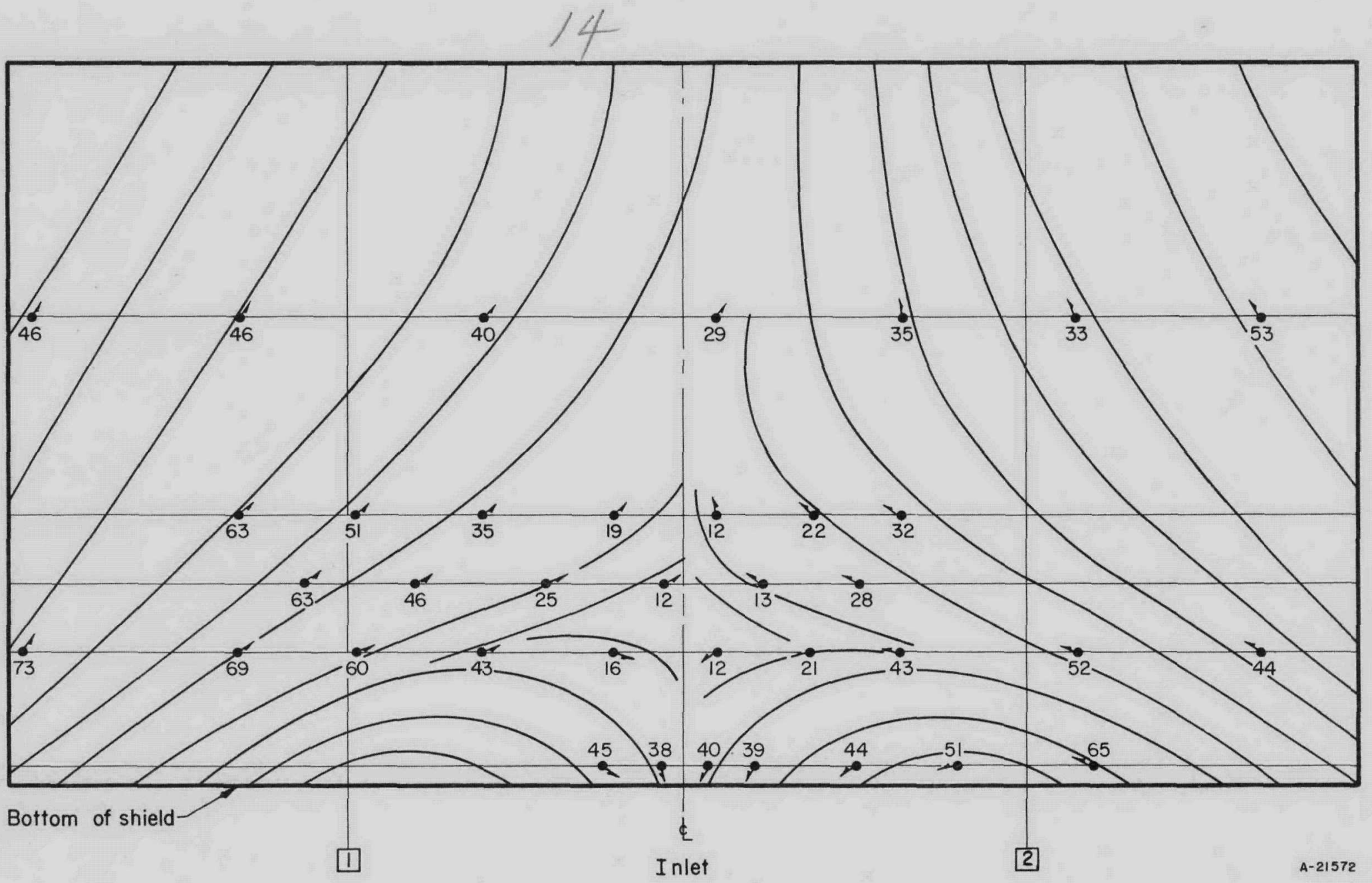

FIGURE 9. ENLARGED DETAIL OF FLOW PATTERN IN CHANNEL 1 WITH THREE-LOOP OPERATION (ENTIRE AREA SHOWN IN FIGURE 8)

Arrows indicate direction and numbers indicate air velocity in fps. 
the pressure differential across the flow baffle was measured with an inclined manometer, the flow through Channel 1 of the shield passages was measured with the yaw probes at the top of the channel, and the total model flow was measured at the model inlets. The flow through the flow baffle was determined as the difference between total model flow and shield-passage flow.

It was then possible to determine the orifice coefficient of the baffle, from

$$
\mathrm{V}=\mathrm{CA} \sqrt{2 \mathrm{gh}}
$$

where

$$
\begin{aligned}
& V=\text { volume rate of flow through baffle } \\
& C=\text { orifice coefficient of baffle } \\
& A=\text { total orifice area of baffle } \\
& g=\text { acceleration of gravity } \\
& h=\text { fluid head across baffle. }
\end{aligned}
$$

Flow-baffle orifice coefficients were found to be constant over a wide range of flows for each inlet arrangement but varied for different inlet arrangements. Figure 10 shows flow-baffle orifice coefficients plotted against air flow through the baffle. Model air flow was varied from $1.23 \mathrm{lb}$ per sec to $5.59 \mathrm{lb}$ per sec. Reynolds numbers in one flow-baffle orifice varied from 8570 to 31,900 with this flow range, and Reynolds numbers in one model inlet, which are indicative of turbulence in the lower plenum, varied from 142,000 to 515,000 . As the number of operating loops was decreased, the coefficient of the flow-baffle orifices decreased. The change appeared to be the result of changes in flow pattern in the lower plenum. As inlets were blocked off, the inlet area was reduced but other areas were not changed. This resulted in flow patterns in which transverse velocities beneath the flow baffle were increased relative to other velocities, causing greater angularity of flow into flow-baffle or ifices with resulting reduced orifice coefficients. In addition, the jet of coolant from each inlet impinged directly on the flow baffle, and probably increased the flow through orifices in the area of impingement, which was proportional to the number of inlets in operation.

Flow-baffle orifice coefficients determined in the quarter-scale flow model were as follows:

\begin{tabular}{lc}
\multicolumn{1}{c}{ Configuration } & Area Coefficient \\
Four-loop flow & 0.85 \\
Three-loop flow & 0.71 \\
Flow from two opposed loops & 0.60 \\
Flow from two adjacent loops & 0.59
\end{tabular}

The distribution of flow between the thermal shield and the flow baffle, and between Channels 2, 3, and 4 of the thermal shield, was determined. Tests were run 


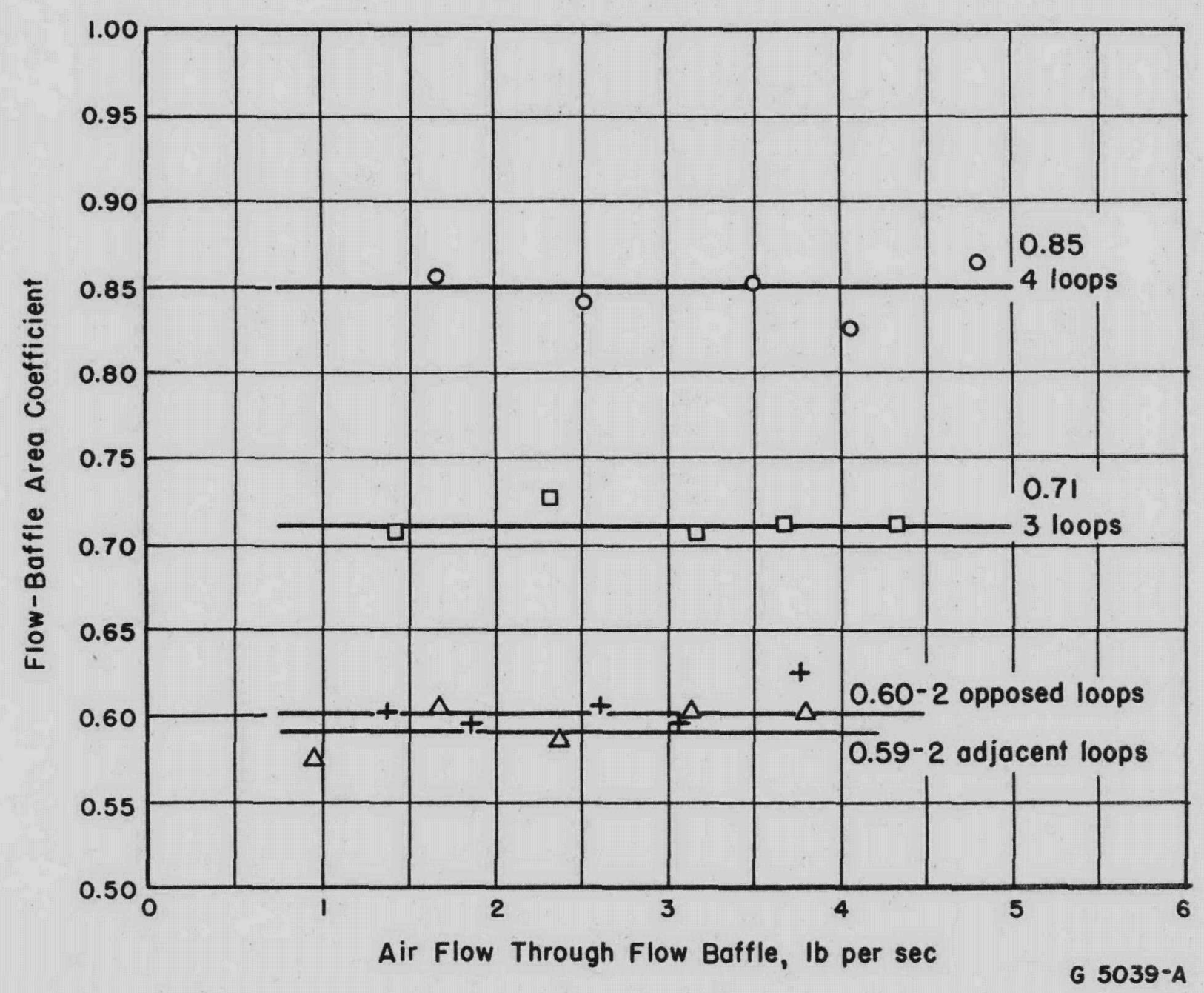

FIGURE 10. RELATION OF AREA COEFFICIENT TOFLOW RATE FOR FLOW BAFFLE IN QUARTER-SCALE MODEL 
with 445 holes in the baffle, and with the outer 24 holes blocked, with various loops operating. The data obtained are given in Table 1. It will be noted in this table that plugging the outer ring of 24 holes in the flow baffle increased the flow rate through the shield passages by about 2 to 3 per cent. The percentage of model flow passing through each shield passage for three-loop conditions agreed closely with the model design values, but changes in operating conditions resulted in changes in shield flow because of changes in flow-baffle orifice coefficients.

TABLE 1. FLOW RATES IN THERMAL-SHIELD COOLANT PASSAGES OF THE QUARTER-SCALE FLOW MODEL

Tests run with 445 holes in flow baffle

\begin{tabular}{|c|c|c|c|c|c|c|}
\hline \multirow{3}{*}{$\begin{array}{c}\begin{array}{c}\text { Operating } \\
\text { Configuration }\end{array} \\
\text { Design values }\end{array}$} & \multicolumn{3}{|c|}{ Total Shield Flow } & \multicolumn{3}{|c|}{$\begin{array}{l}\text { Flow to Each Channel, } \\
\text { percentage of shield flow }\end{array}$} \\
\hline & \multirow{2}{*}{$\frac{\text { Lb per Sec }}{0.618}$} & \multicolumn{2}{|c|}{$\begin{array}{l}\text { Percentage of } \\
\text { Total Flow }\end{array}$} & \multirow{2}{*}{$\frac{\overline{C h a n n e l ~ 2}}{40.0}$} & \multirow{2}{*}{$\frac{\text { Channel } 3}{40.0}$} & \multirow{2}{*}{$\frac{\text { Channel }}{20.0}$} \\
\hline & & 15.0 & - & & & \\
\hline Four loop & 0.637 & 11.5 & $14.4(a)$ & 39.6 & 41.0 & 19.4 \\
\hline Three loop & 0.631 & 14.7 & $17.1^{(a)}$ & 40.7 & 40.3 & 19.0 \\
\hline $\begin{array}{l}\text { Two opposed } \\
\text { loops }\end{array}$ & 0.623 & 16.7 & $18.3^{(a)}$ & 41.3 & 38.0 & 20.7 \\
\hline
\end{tabular}

(a) Value obtained with 421 holes in flow baffle; the outer 24 holes were blocked.

Tests in Quarter-Scale Model With Blank Flow Baffle

In order to obtain data on pressure drop and flow distribution in thermal-shield coolant passages at higher flow rates, the perforated flow baffle was replaced with an unperforated baffle which forced all of the model flow through the shield passages. With this baffle installed, it was possible to increase flow rates through the shield passages by a factor 4.6, increasing the Reynolds number in Channel 1 from 16, 300 to 75, 000 .

Flow distribution between Channel 2 and Channel 3 was constant over the range of flows studied, with 40 per cent of the flow to Channel 2 and 60 per cent to Channel 3.

\section{STUDIES IN 1.5-SCALE MODEL}

The quarter-scale model, because of design changes and the design of the model itself, was not entirely adequate for studying flow in the thermal-shield region. In the quarter-scale model, the channels are narrow with low air velocities so that Reynolds numbers for flow are lower than those required. The orifices and short transfer tubes in the quarter-scale model thermal-shield region are all well rounded at both the inlet and outlet. This was necessary in order to more easily achieve the desired flow rates for studying flow behavior in the model cooling annuli. The model also contained a fourth annulus which was subsequently eliminated in the prototype design. Therefore, 
a supplementary 1.5-scale model of a section of the cooling annuli, including the design changes, was fabricated to provide the required additional data at a higher Reynolds number for flow. The inlet and outlet of the orifices and short tubes were made sharp edged, corresponding to the prototype design. The inlets and outlets are not well rounded in the prototype because of manufacturing considerations.

The purpose of tests of the 1.5-scale flow model of the thermal-shield flow passages was to determine the diameters and flow resistances of orifices and transfer tubes which determined the distribution of flow between Channel 2 and Channel 3 . This required measurement of pressure-loss characteristics of the orifice connecting Channel 1 and Channel 2, and of the transfer tube connecting Channel 1 and Channel 3, and pressure loss in Channel 2 resulting from flow around the cylindrical obstruction formed by transfer tube from Channel 1 to Channel 3. Results of measured pressuredrop characteristics were used, in combination with friction factors applicable to the machined surface of the prototype shield passages, to compute the diameters of orifices and transfer tubes to obtain equal flow through Channel 2 and Channel 3. Accordingly, no effort was made to scale surface roughness in the channels, and channels were shorter than those in the prototype. The length of the model was based on use of $8-\mathrm{ft}$ lengths of steel plate, which were readily available.

DESCRIPTION OF 1.5-SCALE FLOW MODEL OF THERMALSHIELD COOLANT PASSAGES

The 1.5-scale flow model simulated $1 / 32$ of the circumference of the shield passages, a width sufficient to include one orifice and one transfer tube and the corresponding channel flow area. At this scale, the slight curvature of shield channels was not considered important, so the model was constructed of flat steel plates. Channel 1 was $16 \mathrm{in}$. wide and $2-7 / 32 \mathrm{in}$. thick, and was constructed of $1 / 4-\mathrm{in}$. hotrolled steel plate. Channel 2 was $14.56 \mathrm{in}$. wide and $1.125 \mathrm{in}$. thick and was constructed of $1 / 8-\mathrm{in}$, polished stainless steel plate. Channel 3 was $14.06 \mathrm{in}$. wide and 1.173 in. thick and was constructed of 1/8-in. cold-rolled steel plate. The two plates in each channel were spaced at the edges by wood spacers and bolted at close intervals with heavy bolts. The flow area in Channel 2 was 46 per cent, and that in Channel 3 was 46.5 per cent, of the flow area of Channel 1 .

Figure 11 is a photograph of the 1.5 -scale model of the shield passages, and Figure 12 is a schematic drawing showing the arrangement of the channels, the locations of pressure taps, and the model dimensions. This is an accurately scaled drawing of the shield flow passages as modeled, and is comparable to the schematic drawing of Figure 1. The diameter of the orifice connecting Channel 1 and Channel 2 was fixed at $5.25 \mathrm{in}$. throughout the study, simulating a 3.5-in. orifice in the prototype, which was the largest allowable hole diameter from stress considerations and would give the smallest over-all shield pressure drop. The outside diameter of the transfer tube, extending from Channel 1 through Channel 2 to Channel 3 was fixed at 7.5 in., fixing the obstruction in Channel 2. The inside diameter was varied by the use of cylindrical inserts with inside diameters of $4.00,4.69,5.11$, and 6.00 in.

In initial tests it was found that eddy shedding from the cylindrical obstruction in Channel 2 resulted in severe and destructive vibration of the model, and in a very high noise level. The vibrations flexed the channel walls visibly at about $200 \mathrm{cps}$, breaking 


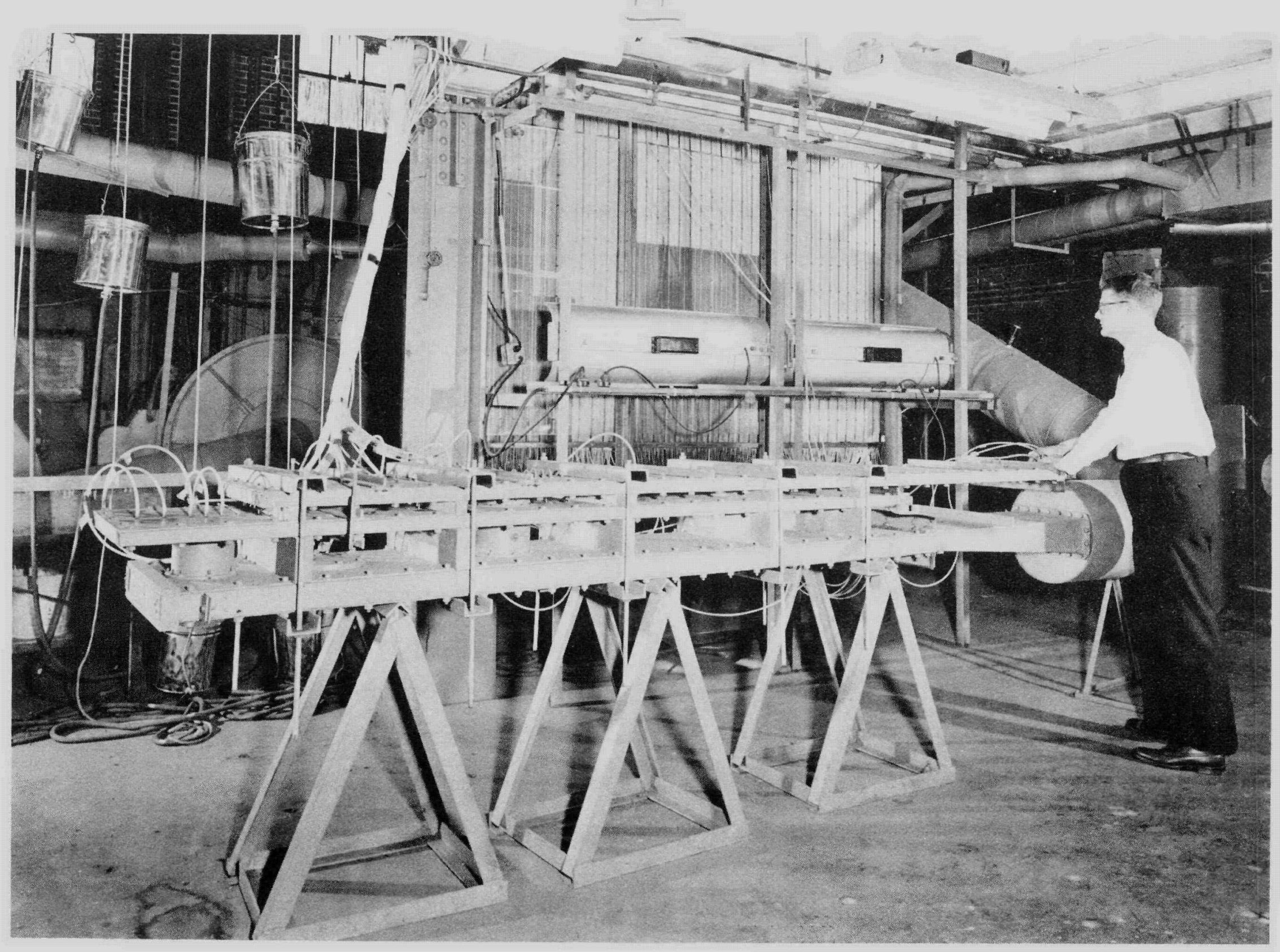

FIGURE 11. 1.5-SCALE FLOW MODEL OF THERMAL-SHIELD FLOW PASSAGES FOR PWR REACTOR 

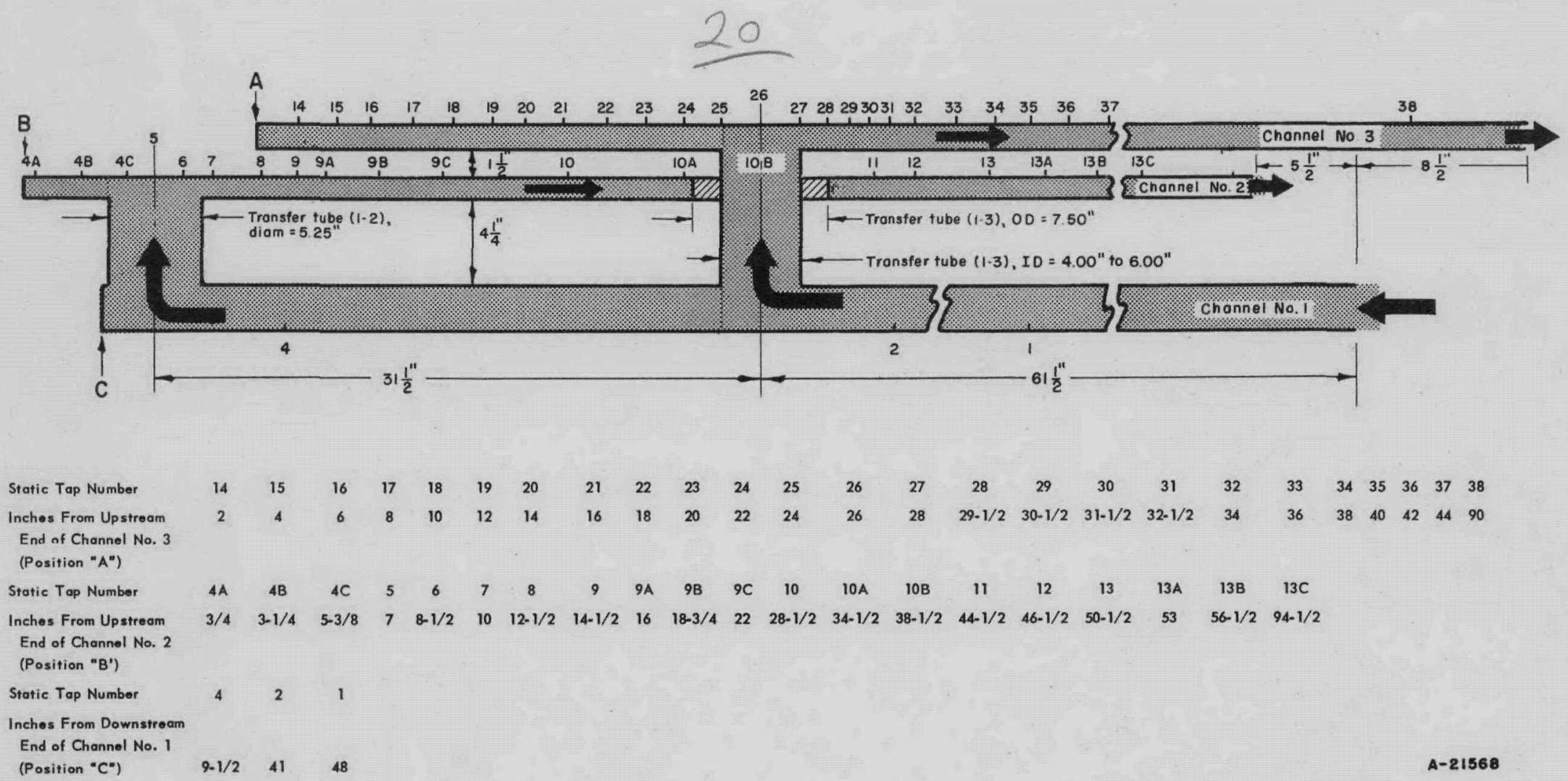

FIGURE 12. SCHEMATIC DRAWING OF 1. 5-SCALE FLOW MODEL OF THE THERMAL SHIELD PASSAGES IN THE PWR REACTOR 
off pressure connections and loosening bolts. The model was stiffened by welding on numerous stiffening bars, and then stiffened further by use of spacers clamped tightly between the channels as shown in Figure 11. This reduced vibration to the extent that tests could be run at air flows to $5 \mathrm{lb}$ per sec. In the prototype similar eddy shedding will occur in the wake of the cylinder, but with the combination of low-velocity, incompressible water flow and extremely rigid construction, vibration should not be a problem.

Instrumentation of 1.5 -Scale Model

The total flow through the 1.5-scale model was measured by a Pitot-tube traverse at the model inlet and checked with an orifice at the inlet of the blower system. Flows in Channels 2 and 3 were measured by 36-point traverses of total and static pressures at the channel outlets, using three-probe rakes at 12 positions.

In Figure 11 a total-pressure rake is being used by the operator to measure flow in Channel 3. Static pressures at various points along the center line of each channel were measured by static-pressure taps in the channel walls. Some of these taps can be seen in Figure 11, and the locations of the taps are indicated in Figure 12.

All pressures were measured with vertical water-filled manometers. For convenience, a portion of the large manometer panel assembled for the quarter-scale flow model was used.

Operation of the 1.5 -Scale Model

The 1.5-scale flow model was set up so that operating conditions could be controlled closely. The flow rate was varied by dampers at the blower outlets. The maximum flow rate used was of the order of $5 \mathrm{lb}$ per sec at a pressure of about 3 psi. At higher flows, model vibration was destructive.

In preliminary studies using the 1.5-scale model, an attempt was made to calibrate Channels 2 and 3 by blocking one channel and passing all the flow through the other. This would have permitted measurement of flow by use of a single pitot tube at the center of each channel. These calibrations proved unsuccessful, as velocity gradients were different when using both channels than when using only one, resulting in indicated flows for two-channel operation 20 per cent higher than the true flow. Therefore, total-pressure and static-pressure rakes were used to make 36-point traverses of the outlets of each channel. Using a 36-point traverse, the flows measured in the inlet duct checked the sums of the flows in Channels 2 and 3 within 2 per cent.

At flow rates of approximately $6 \mathrm{lb}$ per sec, vibration of the model broke off connections to most of the pressure taps in Channel 2. These could not be repaired without disassembly of the model. An analysis of the data using only the undamaged pressure taps showed that additional pressure measurements were required to adequately define the flow behavior in Channel 2. The model was then disassembled, the damaged pressure taps were repaired, and eleven additional static-pressure taps were installed. All data used to determine momentum losses in Channels 2 and 3 were obtained in tests which were run following these changes. 
SUMMARY OF DATA FROM 1.5-SCALE MODEL OF PWR THERMAL-SHIELD COOLANT PASSAGES

The 1.5-scale model was used to obtain data on momentum losses in the upper part of the thermal-shield assembly, where coolant passes (1) from Channel 1 to Channel 2 through a ring of 32 orifices through the shield between Channel 1 and Channel 2 , and (2) from Channel 1 to Channel 3 through a ring of 32 transfer tubes passing through Channel 2. The diameter of orifices from Channel 1 to Channel 2 was fixed at 5.25 in., corresponding to the maximum diameter permitted in the prototype from stress considerations.

For each configuration, data were obtained at several air-flow rates. Data included measurements of static pressures at many points along the center line of each channel, and measurement of flow rates in each of the three channels.

\section{Typical Static-Pressure Data for the 1.5-Scale Mode1}

Figures 13, 14, and 15 show typical static-pressure data for Channels 1, 2, and 3 , respectively. The horizontal dimensions of the three figures are scaled from model dimensions and show the instrumented length extending from the left end (top) of each shield passage. The data shown are with a transfer-tube diameter of $5.11 \mathrm{in}$. Flow rates were: Channel 1, 4.79 lb per sec; Channel 2, 2.14 lb per sec; and Channel 3, $2.65 \mathrm{lb}$ per sec.

In Figure 13, the slight slope of the static-pressure curve from the inlet to the transfer tube is the result of friction. The sudden increase at the transfer tube is the result of the decrease in velocity after diversion of part of the flow through the transfer tube.

In Figure 14, showing flow in Channel 2, the high peak at the left end of the channel corresponds to impact pressure read on pressure taps opposite the orifice from Channel 1. Away from this peak, the pressure drops to the static value, and it can be seen that there is some pressure recovery up to the point where the transfertube influences flow. The transfer tube passes through Channel 2, forming a cylindrical obstruction which blocks 50 per cent of the flow area, and it can be seen that this results in a large pressure drop. After the transfer tube, pressure recovery occurs, followed by friction loss to the end of the channel.

In Figure 15, static pressures for Channel 3 are shown. Impact pressure is again measured opposite the transfer tube, followed by pressure recovery and friction loss to the end of the channel.

Momentum Losses in the 1.5-Scale Model

It is evident that the principal momentum losses were the turning loss in passing from Channel 1 to Channel 3, the turning loss in passing from Channel 1 to Channel 2, and the blockage loss in Channel 2. In analyzing these losses, standard definitions were adopted. These were as follows. 


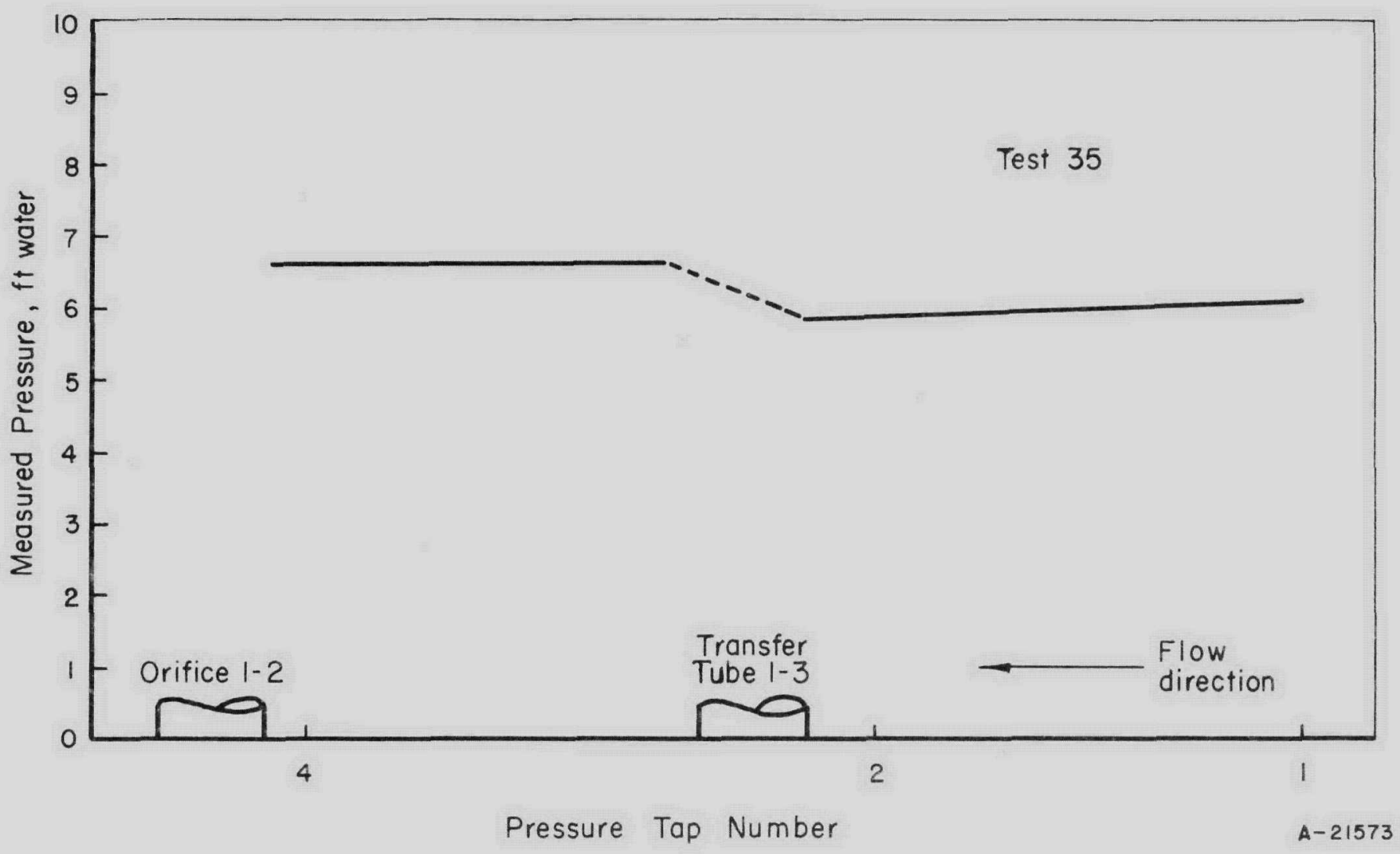

FIGURE 13. PRESSURES MEASURED WITH STATIC TAPS IN CHANNEL 1 OF 1.5SCALE MODEL OF SHIELD PASSAGES 


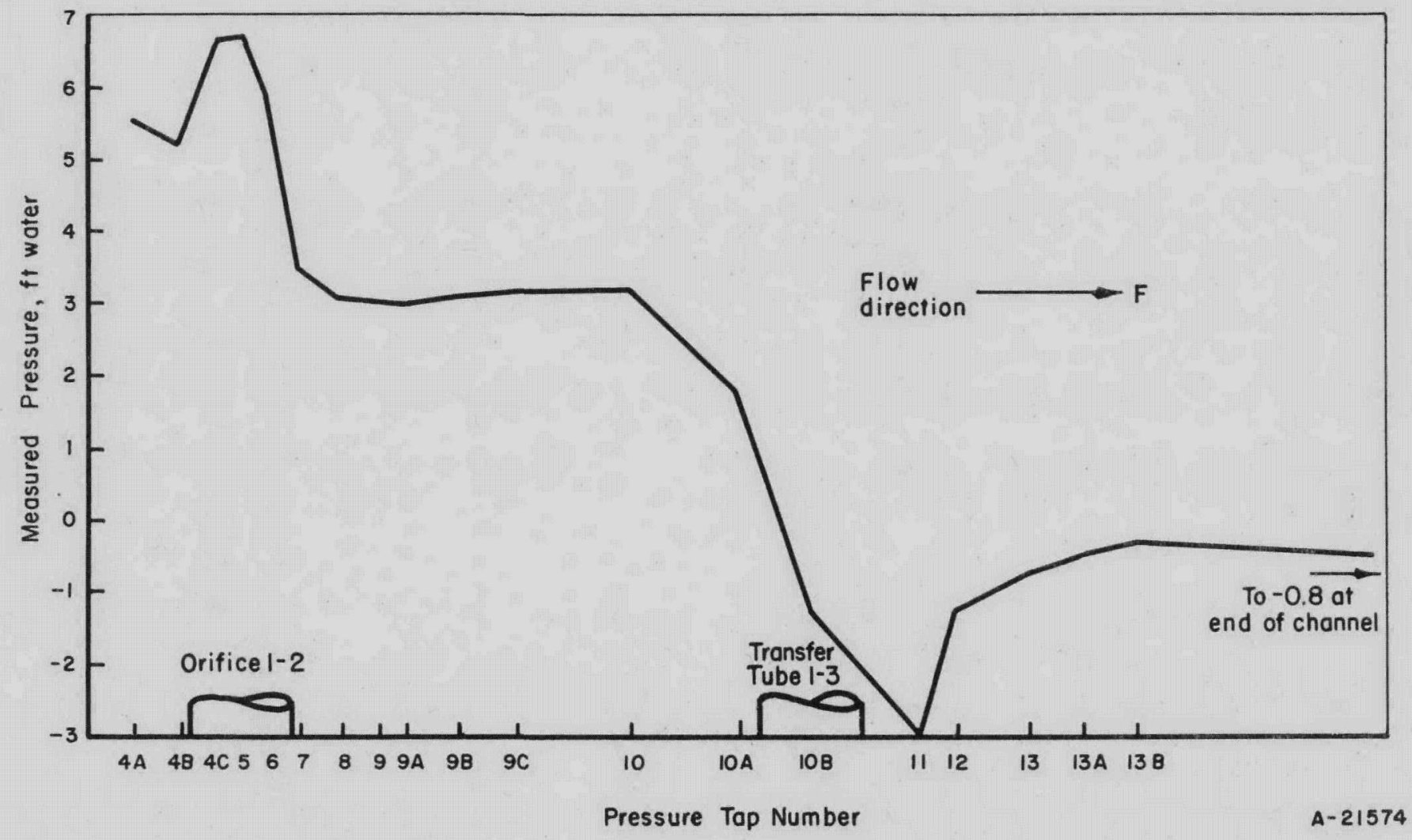

FIGURE 14. PRESSURES MEASURED WITH STATIC TAPS IN CHANNEL 2 OF 1. 5-SCALE MODEL OF SHIELD PASSAGES 


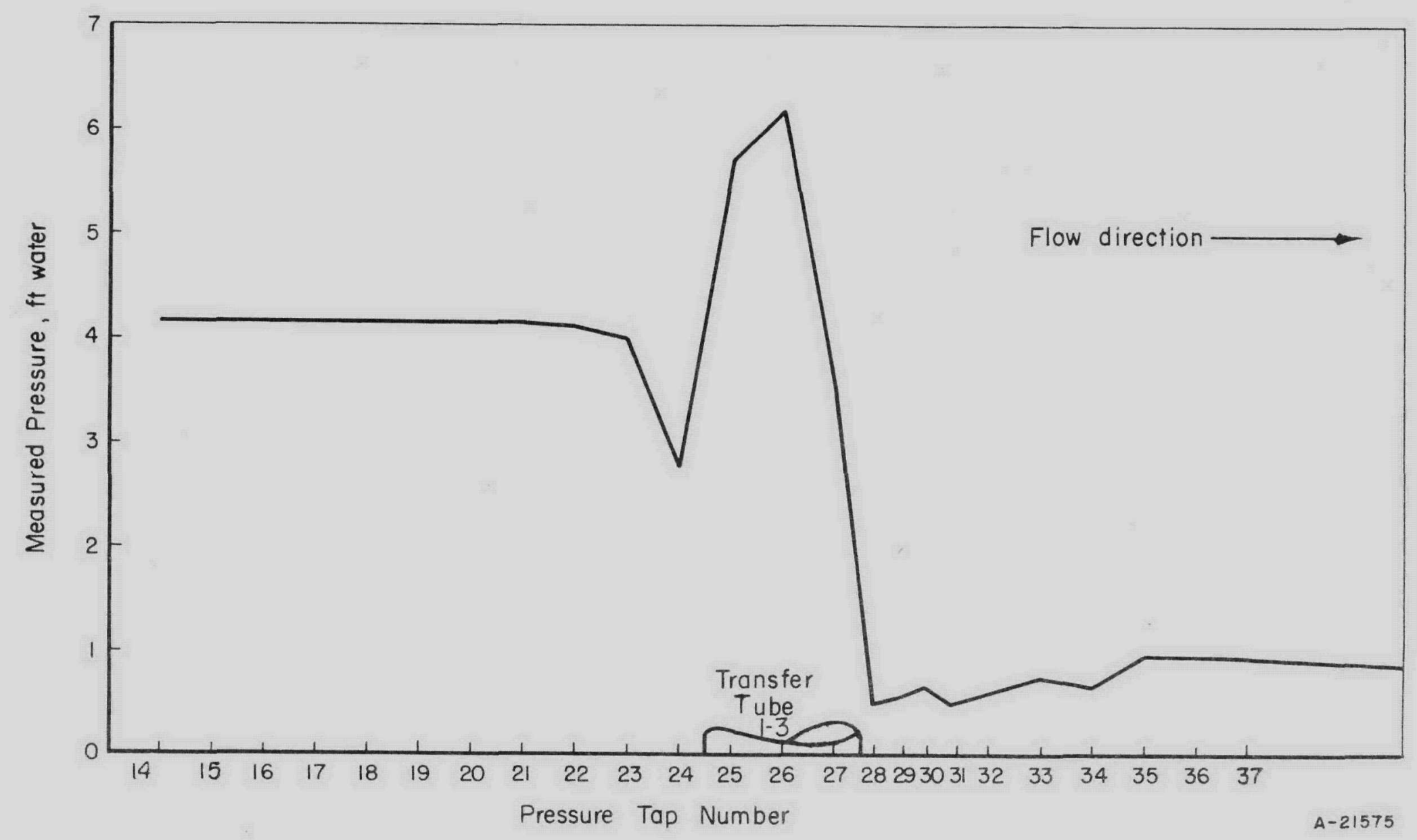

FIGURE 15. PRESSURE MEASURED WITH STATIC TAPS IN CHANNEL 3 OF 1.5-SCALE MODEL OF SHIELD PASSAGES 
The turning loss in Channel 3 is defined as the difference between the total pressure at the entrance of the transfer tube to Channel 3 and the total pressure at the point of highest static pressure in Channel 3 downstream of the transfer tube (pressure difference between Taps 2 and 35). The turning loss for Channel 2 is defined as the difference between the total pressure in Channel 1 at the entrance of the orifice to Channel 2 and the total pressure at the point of highest static pressure reached in Channel 2 downstream of the orifice (pressure difference between Taps 4 and 10). The blockage loss in Channel 2 is defined as the difference between the static pressure upstream from the transfer tube passing through the channel and the highest static pressure after recovery of pressure downstream from the obstruction (pressure difference between Taps 10 and 13B).

In order to place the results in their most usable form, each of the losses was expressed as a loss coefficient, $C_{L}$. The definition for the loss coefficient is:

$$
C_{L}=\frac{\Delta h}{\frac{\left(v^{2}\right)}{2 g}}
$$

Thus, the loss coefficient is the number of velocity heads lost in traversing a particular section. The advantage of expressing the results in this way is that, since the loss is primarily a momentum loss, with viscous effects relatively unimportant, the loss coefficient will be nearly independent of flow velocity.

In the prototype, the total pressure loss can be found by adding the product of loss coefficients and velocity head along a flow path. The velocity head will not vary greatly from one channel to another, because the flow area for Channel 1 is nearly equal to the sum of the flow areas in Channels 2 and 3, and the flow divides about evenly between these channels.

In the model, the same procedure can be used, except that because density of the air used in the model varies appreciably from point to point, it is desirable to make allowances for the density variation. This can be done in the computation of the loss coefficient by using the arithmetic average of inlet and outlet density and velocity. This procedure implies that the air-temperature changes are negligible. In the present case, they are always less than $1 / 2$ per cent, and have no appreciable effect on the accuracy of the results.

It should be pointed out that the variations of air density have no effect on Reynolds number, because the mass flow rate in a channel is constant.

Turning Loss, Channel 1 to Channel 3 for 1.5-Scale Model

Figure 16 summarizes turning losses for flow from Channel 1 to Channel 3, using transfer tubes having inside diameters of $4.00,4.69,5.11$, and 6.00 in. A computed value for a 4.12-in. -ID tube is also shown. Turning losses are expressed as loss coefficients and are plotted against the measured flow rates for Channel 3. 


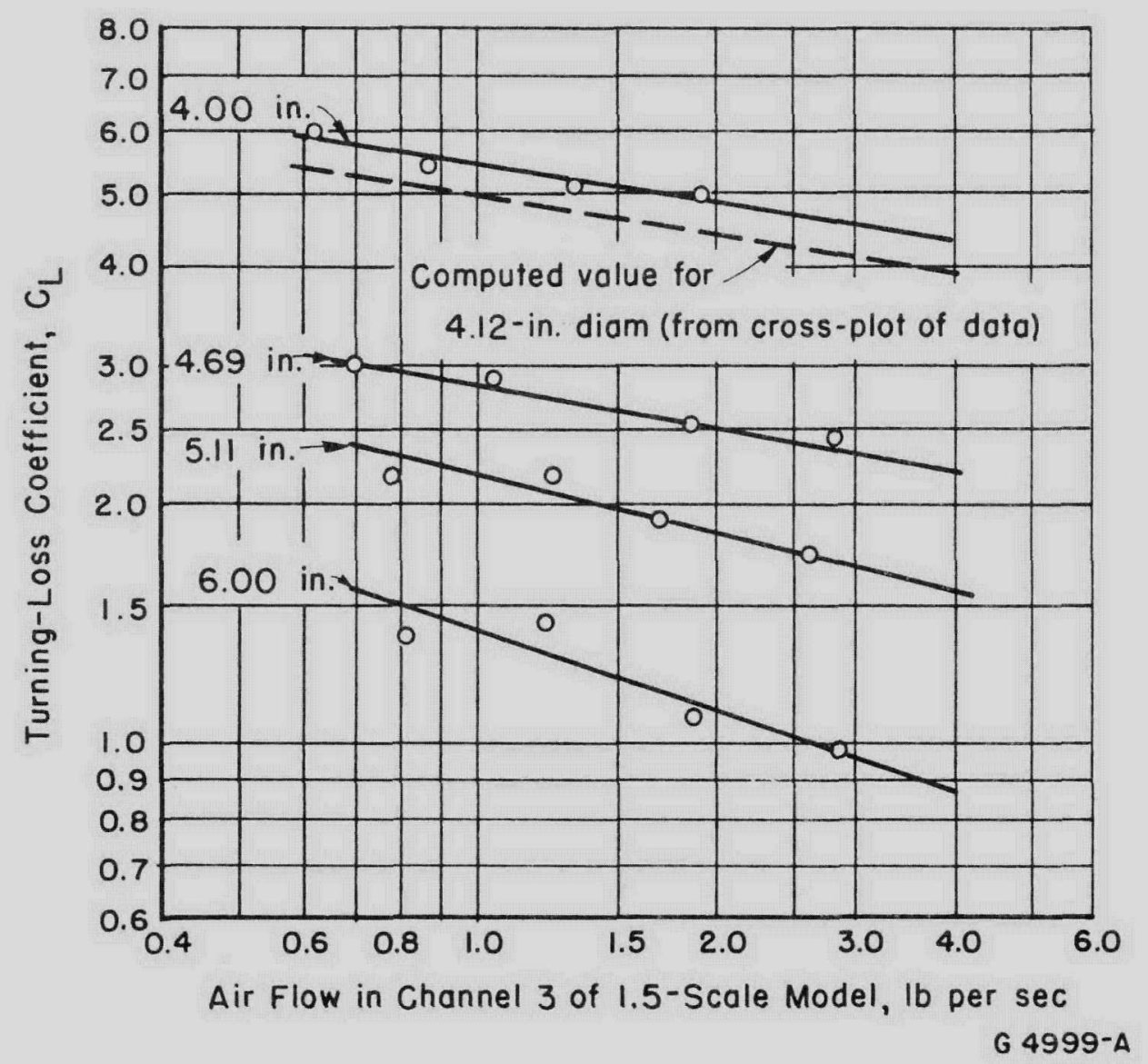

FIGURE 16. TURNING LOSS FOR FLOW FROM CHANNEL 1 TO CHANNEL 3 FOR TRANSFER-TUBE DIAMETERS OF $4.00,4.12,4.69,5.11$, AND $6.00 \mathrm{IN}$. 
Turning Loss, Channel 1 to Channel 2 for 1.5 -Scale Model

Figure 17 summarizes turning losses for flow from Channel 1 to Channel 2. An orifice diameter of $5.25 \mathrm{in}$., simulating the maximum orifice diameter in the prototype, was used throughout the model study. It will be noted that the turning-loss coefficient decreased 15 per cent as flow was tripled.

\section{Analysis of Turning Losses as Orifice Coefficients}

The turning loss involves a deceleration of fluid at the orifice inlet, an entrance into the orifice from a passage in which the height is small compared to the orifice diameter, an exit into a similar passage, followed by recovery of velocity energy, and acceleration down the exit passage. Since the diameter of the orifice or the transfer tube is a primary factor in determining the over-all loss of total pressure, the possibility of expressing the turning losses as orifice coefficients was investigated.

Figure 18 shows orifice coefficients which were calculated assuming all of the turning losses were related to constriction of flow in the orifices. The orifice coefficients are defined by the equation:

$$
\mathrm{V}=\mathrm{CA} \sqrt{2 \mathrm{gh}}
$$

where

$$
\begin{aligned}
& V=\text { volume rate of flow } \\
& C=\text { orifice coefficient } \\
& A=\text { area of orifice } \\
& g=\text { acceleration of gravity } \\
& h=\text { loss of total head across orifice. }
\end{aligned}
$$

Curve 1 is a typical value of orifice coefficient for a sharp-edged orifice in a straight pipe, including velocity of approach factor and recovery of velocity pressure downstream from the orifice.

Curve 2 shows the orifice coefficient required for the measured turning loss from Channel 1 to Channel 2.

Curves 3, 4, and 5 show orifice coefficients which would account for turning losses through transfer tubes from Channel 1 to Channel 3, for diameters of 4.00 in., $5.11 \mathrm{in.}$, and $6.00 \mathrm{in.,}$ respectively. These values all lie in the range of 0.5 to 0.6 , somewhat below values for Curves 1 and 2 . This effect is readily explainable when it is considered that the velocity pressure at the entrance of the transfer tubes is not recovered, as flow continues past the entrance. In addition, the transverse velocity across the inlet would be expected to result in asymmetric flow into the tubes, with a probable reduction in effective flow area. The orifice coefficient decreases as orifice size is increased, showing the increasing importance of entrance and exit restriction. However, even with the narrow coolant passages at the entrance and exit of orifices, the measured flow coefficients are reasonably close to values expected under more usual conditions. When the curves are extrapolated to the range of Reynolds number used in the prototype, orifice coefficients range from 0.63 , for the largest transfer tube, to 0.73 for the Channel 1 to Channel 2 orifice. 


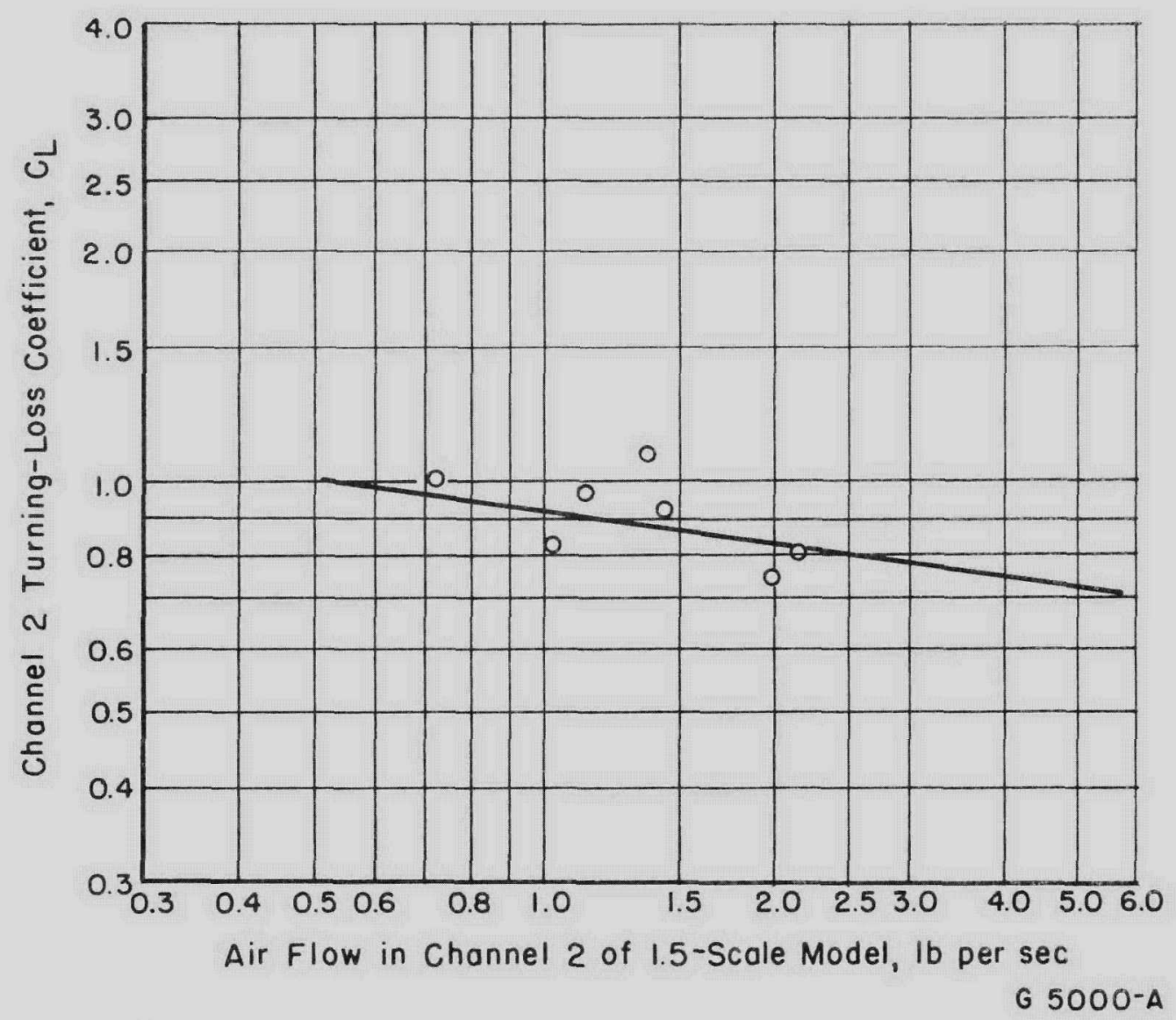

FIGURE 17. TURNING LOSS FOR FLOW FROM CHANNEL 1 TO CHANNEL 2 WITH 5.25-IN. ORIFICE 


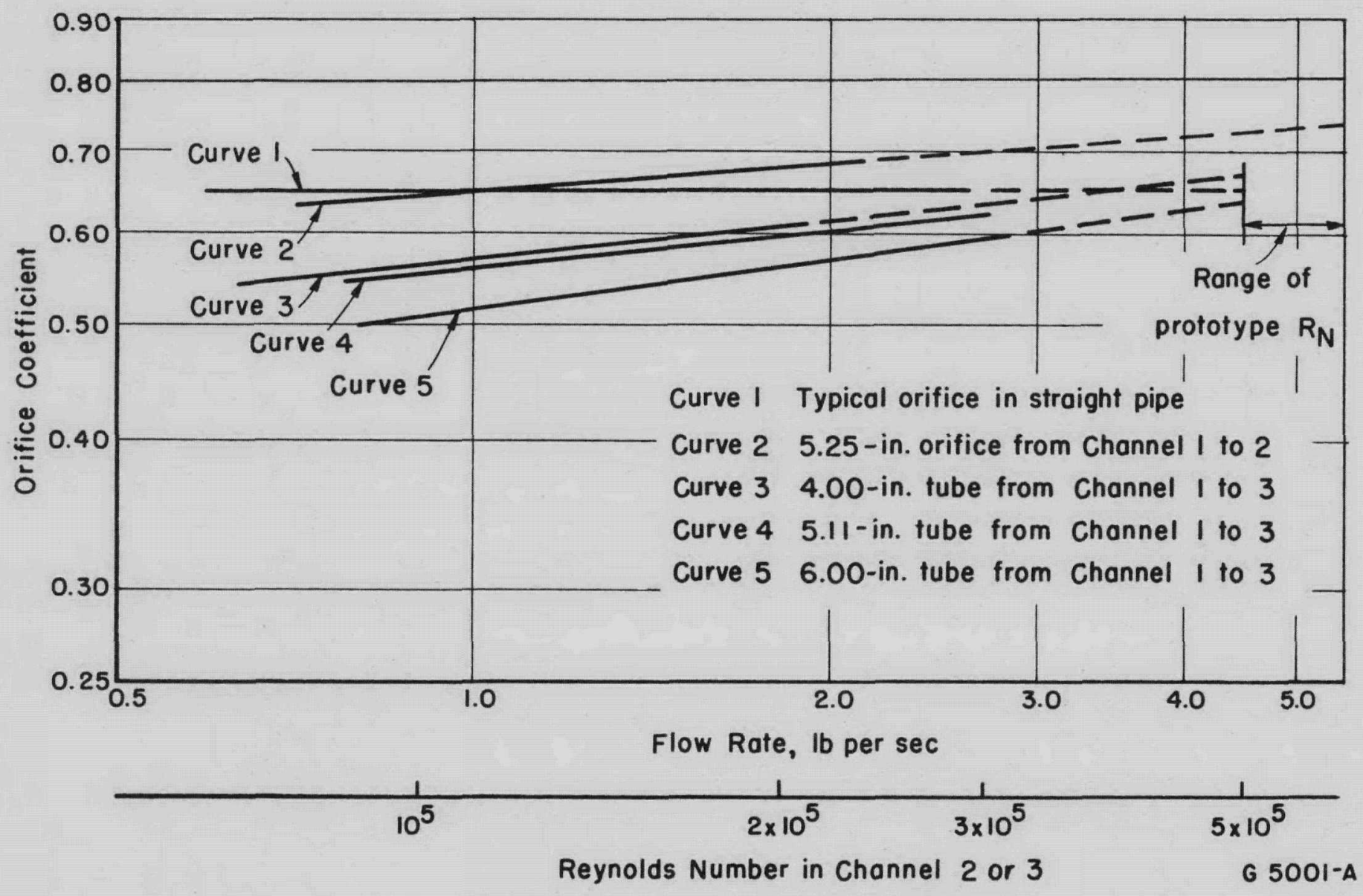

FIGURE 18. TURNING LOSSES IN THE 1.5-SCALE MODEL EXPRESSED AS ORIFICE COEFFICIENTS 
Obstruction Loss in Channel 2 for 1.5-Scale Model

Figure 19 shows the loss for flow around the cylindrical obstruction in Channel 2 , as measured in the 1.5-scale model. Data are expressed as a loss coefficient, and are plotted against flow in Channel 2 .

Curves 1 and 2, the data curves for two different tests, are similar in shape, but vary slightly in position. For both tests, the loss coefficient dropped with increasing flow until a transition point was reached, then rose sharply. The form of the losscoefficient curves can be readily explained in terms of the properties of the system. It appears that the initial decrease in loss coefficient is a Reynolds-number effect, to be expected in this flow range, and that the transition to increasing loss coefficient occurs with the advent of compressibility. Although published data for flow around cylinders in a channel were not available for comparison, data for flow around cylinders in free streams are readily available, and illustrate the drag characteristics for a cylinder, though not necessarily the coefficients which apply in Channel 2.

Curve 3, Figure 19, shows a typical curve for drag coefficient of a cylinder in a free stream, plotted against Channel 2 flow rates corresponding to applicable Reynolds numbers. The drag coefficient is about 1.1 in the region of laminar flow in the boundary layer around the cylinder, with wake separation occurring upstream of the center of the cylinder. With increasing Reynolds number the boundary layer becomes turbulent and separates downstream from the center of the cylinder, resulting in a narrower wake and a reduced drag coefficient of about 0.45. The curve of loss coefficient for the cylindrical obstruction in Channel 2 should be similarly influenced by Reynolds number, with a large drop in loss coefficient occurring with the transition from laminar to turbulent boundary layer. The values of loss coefficient for the cylinder in Channel 2 depend upon percentage of blockage of channel flow area, and, thus, have no relation to the values for a cylinder in a free stream, except by coincidence. It appears probable that the Reynolds number for this transition would be lower for the cylinder in Channel 2 than for a cylinder in a free stream, as the local velocities at the surface of the cylinder in a free stream would be lower for equal approach velocities. It appears evident from the test data that this transition took place in the range of the test conditions. Thus, at the higher Reynolds numbers existing in the prototype, coefficients for turbulent boundary layer can be applied.

The curve to the right of the transition points of Curves 1 and 2 appeared typical for compressible flow, and thus would not be applicable to flow of an incompressible fluid. To check roughly the range of flow in which compressibility effects would occur, an analysis was made based on the assumptions of isentropic expansion to the narrowest part of the channel, followed by sudden enlargement. The results of this analysis are shown in Figure 19, Curve 4. Although the analysis is only approximate, not taking into consideration the partial recovery of velocity pressure which may occur before wake separation, or the velocity gradient from the edge of the channel to the surface of the cylinder, it verifies that flow rates were such that compressibility would be expected to influence results.

It was concluded that the most acceptable curve of loss coefficient for incompressible flow around the cylindrical obstruction in Channel 2 would be that of Curve 5 , which passes through the test points at flows up to those at which compressibility effects are evident, reaches a minimum, then increases gradually with flow. In drawing Curve 5 , it was assumed that the decrease in loss coefficient at the left showed the effect of the transition from laminar to turbulent boundary layer. The lowest value shown in 


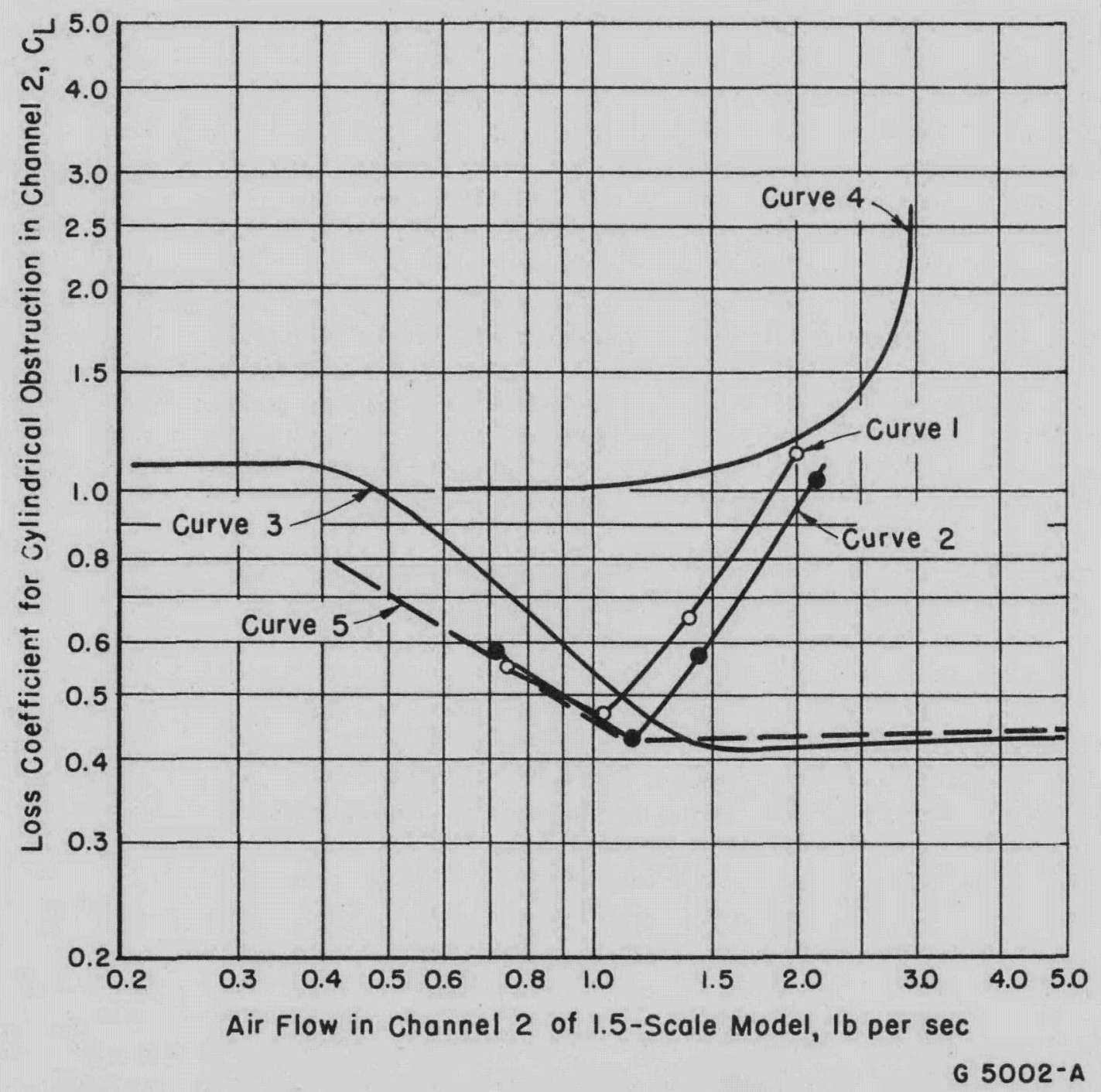

FIGURE 19. LOSS FOR FLOW AROUND CYLINDRICAL OBSTRUCTION IN CHANNEL 2 OF 1.5-SCALE FLOW MODEL 
Curve 5 was taken as the lowest measured value. There is some possibility that, with incompressible flow, the curve might have continued downward to a somewhat lower value at a greater Reynolds number. Compressibility effects in the model would have masked such a result. However, the value of loss coefficient in the range of interest is about 0.45 , which is only about 5 per cent of the total pressure loss in the shield passages. Thus, a further reduction in the value of loss coefficient would have almost no effect on shield flow or flow distribution.

Relation of Momentum Loaases to Reynolds

Number for 1.5-Scale Model

In applying loss coefficients from the 1.5 -scale model, it is convenient to relate them to Reynolds number, which can then be used as a basis for applying the results under prototype conditions.

Figure 20 shows the relation between los coefficients and Reynolds number. The dashed extensions of the curves are extrapolations to prototype Reynolds numbers, which are indicated on each curve. Curves were determined from Figures 14, 15, and 17, with Reynolds numbers determined from flow rates in the model.

\section{APPLICATION OF MODEL DATA TO DESIGN OF PROTOTYPE} SHIELD COOLANT PASSAGES

Flow Distribution and Pressure Loss in Shield Passages

Dimension of the flow areas in the shield passages and in the flow baffle were established on the basis of experimental data to provide approximately 15 per cent of the reactor flow through the shield coolant passages under four-loop operating conditions. Dimensions established were as follows:

$$
\begin{array}{lr}
\text { Diameter of } 32 \text { orifices from Channel } 1 \text { to Channel } 2 & 3.50 \mathrm{in.} \\
\text { Diameter of } 32 \text { transfer tubes from Channel } 1 \text { to Channel } 3 & 2.75 \mathrm{in.} \\
\text { Diameter of } 421 \text { orifices in flow baffle } & 1.90 \mathrm{in} .
\end{array}
$$

After refinement of data and data analysis procedures, the flow through the shield region was found to be 16.3 per cent of reactor flow under four-loop conditions, 18. 8 per cent under three-loop conditions, and 21.7 per cent under two-loop conditions.

The loss coefficients which were used in computing flow in prototype-shield passages are summarized below: 


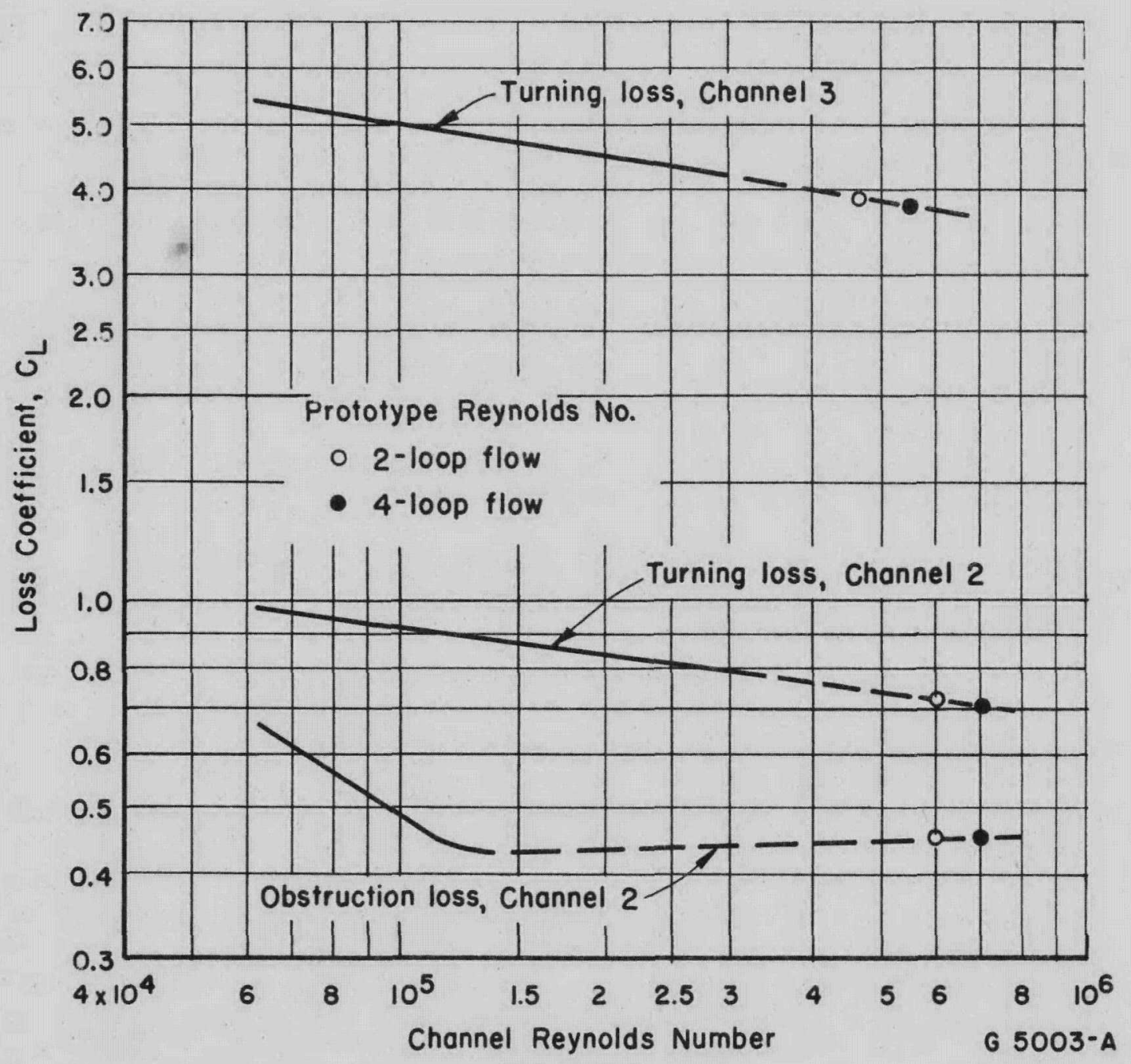

FIGURE 20. RELATION OF LOSS COEFFICIENTS TO REYNOLDS NUMBER FOR 1.5-SCALE MODEL 


\begin{tabular}{|c|c|c|}
\hline Loss & & $\mathrm{C}_{\mathrm{L}}$ \\
\hline Friction loss, Channel 1 & & 0.75 \\
\hline Turning loss, Channel 1 to Channel 2 & (From & Figure 20) \\
\hline Obstruction loss, Channel 2 & & 0.45 \\
\hline Friction loss, Channel 2 & & 1.80 \\
\hline Exit loss, Channel 2 & & 1.00 \\
\hline Turning loss, Channel 1 to Channel 3 & (From & Figure 20) \\
\hline Friction loss, Channel 3 & & 1.56 \\
\hline Exit loss, Channel 3 & & 1.00 \\
\hline
\end{tabular}

The friction loss in each of the channels was calculated using the Fanning equation, $f(L / D)\left(V^{2} / 2 g\right)$. A friction factor, $f$, of 0.02 was used as being appropriate for the machined surface of the prototype, with the appropriate channel length and a value of $\mathrm{D}$ of twice the channel thickness. The term $\mathrm{V}^{2} / 2 \mathrm{~g}$ is the velocity head and was not included at this step, leaving the term $f(L / D)$ as a loss coefficient comparable to those for momentum losses.

The exit loss from Channels 2 and 3 was taken as one velocity head, as it was assumed that the velocity leaving the channels was dissipated in the lower plenum without appreciable pressure recovery.

Figure 21 shows the relation of pressure drop to water flow for the thermalshield passages and flow baffle in the prototype.

The Channel 1 pressure loss was determined by assuming several flow rates, calculating the velocity pressure for each flow rate, and multiplying the velocity pressure by the friction-loss coefficient of 0.75 . The Channel 2 and Channel 3 pressure losses were determined by assuming several flow rates for each channel and calculating the Reynolds number and velocity pressure for each flow rate assumed. With the Reynolds number known, the appropriate turning-loss coefficient was selected from Figure 20. The total loss coefficient was then calculated as the sum of the loss coefficients for the channel under consideration. The pressure loss for each point was the product of the total loss coefficient and the velocity pressure.

Curves relating pressure loss for the flow baffle to flow rate for two-loop, threeloop, and four-loop flow are also included in Figure 21. These curves are based on the use of a flow-baffle hole pattern identical to that used in the quarter-scale model after 24 holes at the periphery of the baffle had been plugged, leaving 421 holes. The diameters of these holes had been set at $1.90 \mathrm{in}$, based on orifice coefficients measured in tests of the quarter-scale model, and on the pressure drop required to obtain a nominal value of 15 per cent of reactor flow through the shield passages. The curves for the flow baffle in Figure 21 show the relation of pressure loss to flow for this hole size. The three curves for different operating conditions are required by changes in orifice coefficients with operating configuration, as discussed earlier in this report. 


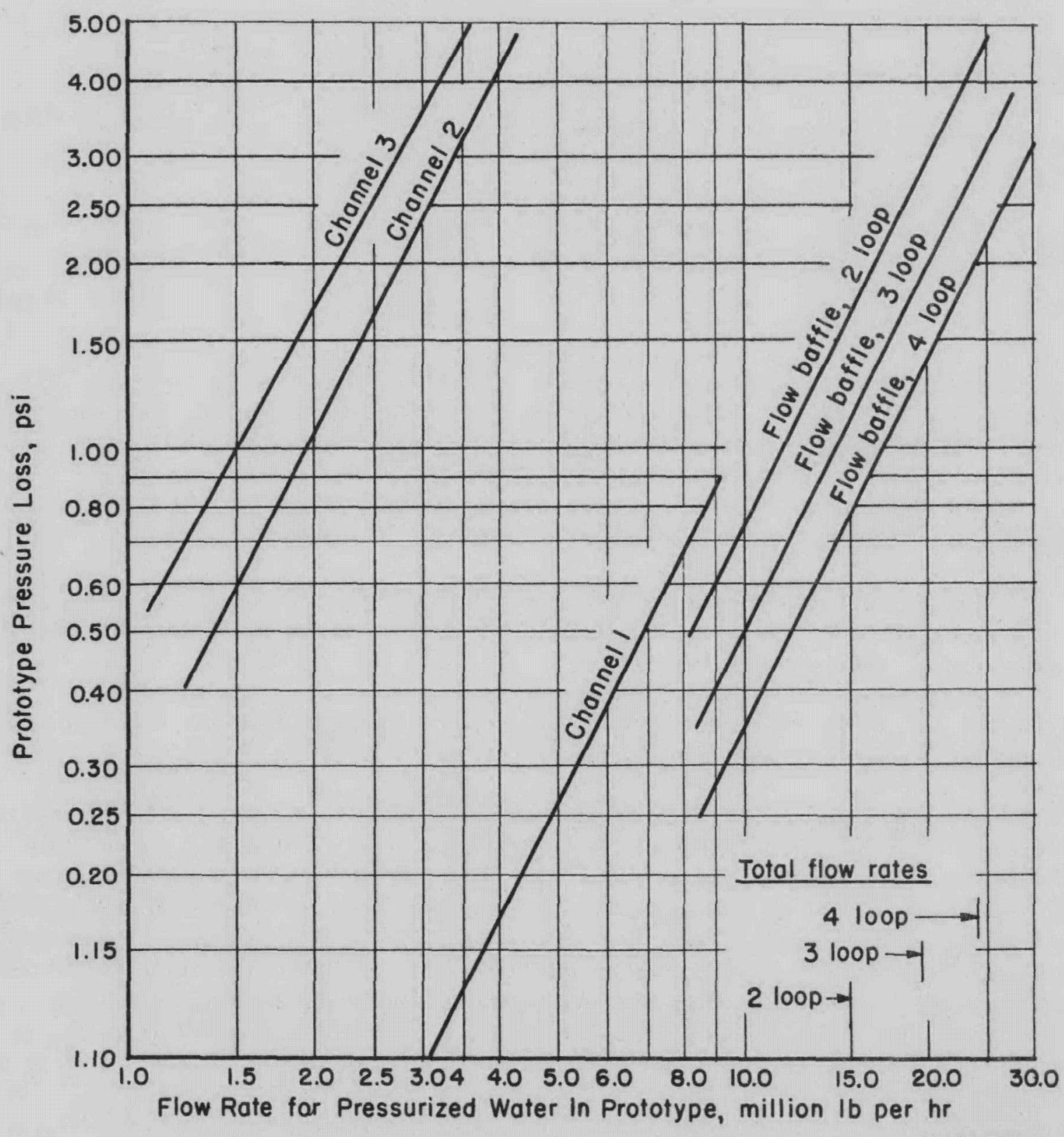

G 5004-A

FIGURE 21. RELATION OF PRESSURE LOSSES TO WATER FLOW RATES IN PROTOTYPE SHIELD PASSAGES AND FLOW BAFFLE 
Using the curves of Figure 21 , it was possible to compute by successive trials the total flow through the shield coolant passages, the distribution of flow between Channel 2 and Channel 3, and the pressure drop for the shield passages and the flow baffle for each operating condition.

For each calculation, it was assumed that the pressure drop in Channel 2 was equal to that in Channel 3. For a selected value of flow in Channel 2, the pressure drop was taken from the curve and, at the same pressure drop, the flow through Channel 3 was taken from the Channel 3 curve. The sum of these two flows was taken as the Channel 1 flow, and the pressure drop for Channel 1 at this flow was taken from the Channel 1 curve. The total shield-passage pressure drop was the sum of the pressure drops for Channel 1 and for Channel 2 or 3 . This value must be equal to the flow-baffle pressure drop. The flow through the flow baffle was determined by subtracting the shield-passage flow from the total coolant flow. Using this flow and the appropriate pressure loss curve from Figure 19, the flow-baffle pressure loss was determined. If this value was equal to the shield-passage pressure loss, the assumed values of flow in Channel 2, and all subsequent computed values, were correct.

Using successive trials, the shield-passage flow rates and pressure losses were determined for four-loop, three-loop, and two-loop operation. These flow rates were then divided by total prototype coolant rates and expressed as percentages of total coolant rates. Total prototype coolant flow rates used throughout the calculations were 23. 7, 19.4, and 15.1 $\times 10^{6} \mathrm{lb}$ per $\mathrm{hr}$ for four-loop, three-loop, and two-loop operation, respectively. The resulting percentages of flow and pressure drops are summarized in Table 2, which also includes results assuming 2 per cent leakage through a seal at the top of Channel 3.

Effects of Leakage Through Seal at Top of Channel 3

on Shield Flow

A labyrinth seal may be used at the top of Channel 3 to seal the core cage into the surrounding structure. The pressure drop across this seal would be the full core pressure drop of about 50 psi, so that appreciable leakage could occur. This leakage would be upward from the top of Channel 3, reducing the downward flow of coolant through Channel 3. In order to evaluate the effects of this leakage, the flow in the shield passages was calculated for four-loop and three-loop operation, assuming leakage of 2 per cent of total coolant flow.

Table 2 summarizes shield-passage flow rates and pressure drops. Column 1 shows the flow distribution anticipated in the reactor shield passages with the present geometry and without seal leakage for four-loop operation.

Column 2 shows the flow distribution calculated for four-loop operation with leakage of 2 per cent of reactor coolant flow through the seal. This condition would result in a downward flow in Channel 3 of 5.81 per cent of reactor coolant flow.

Column 3 and Column 4 show similar data for three-loop operation without seal leakage and with 2 per cent leakage, respectively. With three-loop flow, and with 2 per cent seal leakage, 7.02 per cent of the reactor coolant flows downward in Channel 3 .

Column 5 shows the distribution of flow in shield passages for two-loop operation, 
TABLE 2. SUMMARY OF CALCULATED FLOW RATES FOR THERMAL-SHIELD PASSAGES

Assumed Geometry:

Diameter of Channel 1-Channel 3 Transfer Tube

Diameter of Channel 1-Channel 2 Orifice

2. 75 In

Flow-Baffle Orifice Diameter

3. $50 \mathrm{In}$

Number of Flow-Baffle Orifices

1. $90 \mathrm{In}$.

421

Two-Loop

Three-Loop Operation

Operation

Four-Loop Operation

\begin{tabular}{cc}
\hline $\begin{array}{c}\text { Without Seal } \\
\text { Leakage }\end{array}$ & With 2 Per \\
Cent Leakage
\end{tabular}

0.85

0.85

2,0

0

2. 0

0

\section{Channel 3}

Total Flow Through Shield Passages

Flow Through Channel 2

Flow Into Channel 3

Downward Flow in Channel 3

Flow Through Flow-Baffle

Flow-Baffle Pressure Loss, psi
16.26

16.80

18.81

8.99

10.56

7.81

8.25

5. 81

8.25

83.20

81.19

1.375

83.74

1.40

7.14
19.53

21. 74

1.255

10.51

12.26

9.02

9.48

7.02

9.48

80.47

78.26

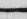


and without seal leakage. Because of the reduced flow-baffle orifice coefficient, the total shield-passage flow rate is 21.79 per cent.

\section{ACKNOWLEDGMENTS}

The work reported was performed by L. J. Flanigan, J. E. Huggins, R. L. Richardson, C. Pollock, J. D. Hummell, and R. A. Johnston, under the supervision of Herbert R. Hazard. The work was done under WAPD reference No. 73 (14-452). Mr. Frank Grochowski, of the Westinghouse Atomic Power Division, coordinated the work for Westinghouse and contributed much to the over-all planning of the research. His assistance is appreciated.

LJF:HRH/rh 